\title{
POLICY DURATION EFFECT UNDER ZERO INTEREST RATES: AN APPLICTION OF WAVELET ANALYSIS
}

\author{
KUNIO OKINA \\ SHIGENORI SHIRATSUKA
}

CESIFO WORKING PAPER NO. 1138

CATEGORY 6: MONETARY POLICY AND INTERNATIONAL FINANCE

FEBRUARY 2004

Presented at Venice Summer Institute, Workshop on Economic Stagnation in Japan July 2003

\footnotetext{
An electronic version of the paper may be downloaded

- from the SSRN website:

www.SSRN.com

- from the CESifo website:

www. CESifo.de
} 


\title{
POLICY DURATION EFFECT UNDER ZERO INTEREST RATES: AN APPLICATION OF WAVELET ANALYSIS
}

\begin{abstract}
A major feature of recent monetary policy in Japan has been heavy reliance on the so-called policy duration effect. This policy employs a commitment to compensate for the central bank's inability to lower the interest rate below zero by altering the anticipated course of monetary policy actions. This paper analyzes the behavior of the yield curve and examines the effectiveness and limitations of monetary policy commitment under zero interest rates with four indicators for policy duration effect. Specifically, we extend our previous study (Okina and Shiratsuka (2003)) by applying wavelet analysis to indicators for policy duration effect. As in the previous study, the policy duration effect was found to be highly effective in stabilizing market expectations for the path of short-term interest rates, thereby reducing longer-term interest rates and flattening the yield curve. The policy duration effect, however, failed to reverse deflationary expectations in financial markets.
\end{abstract}

Keywords: zero interest rate policy, quantitative monetary easing, policy duration effects, policy commitment, wavelet analysis.

JEL Classification: E31, E43, E52.

Kunio Okina

Institute for Monetary and Economic Studies Bank of Japan

2-1-1 Nihonbashi-Hongokucho

Chuo-ku, Tokyo 103-8660

Japan

kunio.okina@boj.or.jp
Shigenori Shiratsuka

Institute for Monetary and Economic Studies Bank of Japan

2-1-1 Nihonbashi-Hongokucho

Chuo-ku, Tokyo 103-8660

Japan

shigenori.shiratsuka@boj.or.jp

We appreciate helpful comments on our previous study from Bill Gavin, Michael Hutchison, Ken Kuttner, Makoto Saito, Pierre Siklos, and Tsutomu Watanabe; from the participants of the workshop at Claremont McKenna College, the seminar at the Board of Governors of Federal Reserve System the Federal Reserve Bank of New York, and the International Monetary Fund, and CESifo Venice Summer Institute; from the panelists at the 2003 spring meeting of the Japan Society of Monetary Economics; from the staff of the Policy Planning Office, Financial Markets Department, Research and Statistics Department, and Institute for Monetary and Economic Studies of the Bank of Japan. We would also like to thank Hiroyuki Oi and Masakazu Inada for their superb research assistance. The views expressed in the paper are those of the authors and do not necessarily reflect those of the Bank of Japan or the Institute for Monetary and Economic Studies. 


\section{Introduction}

This paper analyzes the behavior of the yield curve and examines the effectiveness and limitations of monetary policy commitment in Japan's recent deflationary economic environment.

In February 1999, the Bank of Japan (BOJ) began to lower gradually the overnight call rate to 0.02 percent. In April that year, Governor Hayami of the Bank of Japan announced the BOJ's commitment to a zero interest rate until deflationary concerns were dispelled. Then in August 2000, in view of clear signs of a sustained recovery in the economy, the BOJ terminated its zero interest rate policy and raised the overnight call rate to 0.25 percent.

However, in late 2000, the economy once again slowed, reflecting adjustments in the area of global information technology related to investments and exports. As a result, deflationary concerns intensified. The BOJ reacted by lowering the policy interest rate to 0.15 percent in mid-February 2001, and at the end of March it adopted a policy of "quantitative monetary easing." In an effort to stabilize CPI inflation at or above zero percent, the BOJ then committed itself to targeting the current account balance. This led the overnight call rate to decline initially to 0.01 percent, below the 0.02 percent low experienced under the BOJ's zero interest rate policy. Then, in September 2001, the rate further declined to 0.001 percent due to the reduction of the interest rate unit for call market transactions from $1 / 100$ percent to $1 / 1000$ percent.

Even when short-term interest rates have declined to virtually zero, a central bank can produce further easing effects by a policy commitment. ${ }^{1}$ Moreover, a central bank can influence market expectations by making an explicit commitment to the duration for which it will hold short-term interest rates at virtually zero. If it succeeds in credibly extending its commitment duration, it can reduce long-term interest rates. We call this mechanism the "policy duration effect," after Fujiki, Okina, and Shiratsuka (2000) and Fujiki and Shiratsuka (2002).

Recent BOJ monetary policy has been characterized by a heavy reliance on the policy duration effect. As mentioned before, under the zero interest rate policy, the

\footnotetext{
1 See Reifschneider and Williams (2000), Jung, Teranishi, and Watanabe (2001), and Eggertsson and Woodford (2003) for detailed discussions on the policy commitment effect when a central bank faces a zero boundary of nominal interest rates.
} 
BOJ committed to a zero interest rate until deflationary concerns were dispelled, and under the quantitative monetary easing, the BOJ has committed itself to providing ample liquidity that easily exceeds the required reserve until CPI inflation stabilizes at or above zero percent. These policy frameworks employ a policy commitment to compensate for the central bank's inability to lower rates below zero by altering the anticipated course of monetary policy actions.

Okina and Shiratsuka (2003) focus on the policy duration effect by analyzing the behavior of entire yield curves under the past zero interest rate policy, as well as the current quantitative monetary easing. In Okina and Shiratsuka (2003), we take a twostep approach. The first step is to employ a curve-fitting method to estimate a forward rate curve by using a set of spot rates with different time-to-maturity for every day, and to compile indicators for the policy duration effect. ${ }^{2}$ The second step is to examine the changes in the shape of yield curves and the indicators over time, thereby assessing the impacts of the policy duration effect.

In Okina and Shiratsuka (2003), we concluded that the policy duration effect was highly effective in stabilizing market expectations for the path of short-term interest rates, thereby bringing down longer-term interest rates and flattening the yield curve. However, under conditions of low economic growth, the policy duration effect failed to reverse deflationary expectations in the financial markets for the sample period. The expectation of prolonged deflation was most typically observed in reduced long-term interest rates, indicating market expectations of sustained deflation for some years rather than a rapid reversal. In this paper, we extend our previous analysis of Okina and Shiratsuka (2003) by applying wavelet analysis to indicators for policy duration effect to check the robustness of our aforementioned conclusions.

The paper is organized as follows. Section II summarizes the analytical framework employed in Okina and Shiratsuka (2003) for estimating the policy duration effect, based on information contained in the yield curve. Section III provides an overview of data and estimation results, including an assessment on the effectiveness of the policy duration effect, shown in of Okina and Shiratsuka (2003). Section IV

\footnotetext{
2 Assessment of the policy duration effect from observed interest rates can be based on two methods: a direct introduction of policy duration effect into a structural model for interest rate dynamics, or analysis of the time-series movement of the shape of the yield curve. We take the latter approach, while Marumo et al. (2003) take the former.
} 
reports the results of wavelet analysis to the four indicators for policy duration effect. Section V offers a concluding discussion. Moreover, Appendix 1 provides numerical examples of how changes in the parameter values of our yield curve model affect the shape of the instantaneous forward rate curve, and Appendix 2 summarizes the basic framework of wavelet analysis.

\section{Analytical Framework}

In this section, we briefly review the basic framework for the analysis of the policy duration effect employed by Okina and Shiratsuka (2003). We first define the policy duration effect, and then examine how to assess such effects. In addition, we explain the extended versions of Nelson and Siegel's (1987) model to estimate the shape of the yield curve over time. We then introduce indicators for policy duration effect, based on the estimates of the extended Nelson-Siegel model.

\section{A. The Policy Duration Effect}

The policy duration effect arises from expectations concerning how long the current abundant provision of funds (quantitative easing) will last in the future, rather than the current availability of funds.

The BOJ's zero interest rate policy, associated with its commitment to sustaining this policy until deflationary concerns are dispelled, and quantitative monetary easing with a similar commitment later, are both highly effective in stabilizing market expectations for the path of short-term interest rates. Guiding the overnight rate to virtually zero for a considerable period of time serves to anchor medium- to long-term interest rates. As a result, the yield curve flattens and stabilizes at very low levels.

The above policy duration effect mechanism is underpinned by the expectations hypothesis regarding the term structure of interest rates. The pure expectations theory of the term structure of interest rates tells us that long-term interest rates today should reflect the future course of short-term interest rates. ${ }^{3}$ For example, a one-year interest rate is determined by market expectations for overnight interest rates during the subsequent twelve-month period. Based on a more practical and general formula, longterm interest rates are the sum of market expectations for the path of short-term interest

3 See Goodfriend (1998) regarding an excellent discussion on the use of the term structure of interest rates for monetary policy analysis. 
rates and a term premium (based on risks posed by uncertainties or preferences of market participants). With premiums being constant, fluctuations of interest rates on term instruments reflect changes in expectations. ${ }^{4}$

\section{B. The Extended Model of Nelson and Siegel (1987)}

We employ an extended version of Nelson and Siegel's (1987) model, proposed by Söderlind and Svensson (1997). ${ }^{5}$

Our specification of the instantaneous forward rate (IFR) for a settlement at period $m$, denoted by $r(m)$, is

$$
r(m)=\beta_{0}+\beta_{1} \cdot \exp \left(-\frac{m}{\tau_{1}}\right)+\beta_{2} \cdot\left(\frac{m}{\tau_{1}}\right) \cdot \exp \left(-\frac{m}{\tau_{1}}\right)+\beta_{3} \cdot\left(\frac{m}{\tau_{2}}\right) \cdot \exp \left(-\frac{m}{\tau_{2}}\right),
$$

where $\beta_{0}, \beta_{1}, \beta_{2}, \beta_{3}, \tau_{1}$ and $\tau_{2}$ are parameters to be estimated from the data. We expect $\beta_{0}, \tau_{1}$ and $\tau_{2}$ to be positive.

The IFR curve, generated by equation (1), includes four terms. The first term is a constant $\beta_{0}$. The second term is an exponential function $\beta_{1}^{*} \exp \left(-m / \tau_{1}\right)$. When $\beta_{1}$ takes a negative (positive) value, this term produces an upward-trending (downwardtrending) shape in the short end of the IFR curve. A large (small) value of $\tau_{1}$ means that this exponential effect decays more slowly (quickly). The third term is $\beta_{2}^{*}\left(m / \tau_{1}\right) * \exp \left(-m / \tau_{1}\right)$, producing a U-shape (hump shape) when $\beta_{2}$ takes a negative (positive) value. The fourth term produces a U-shape (hump shape) when $\beta_{3}$ takes a negative (positive) value. $\tau_{2}$ controls the rate of convergence of the fourth term, as does $\tau_{1}$ for the second and third terms.

The specification for the spot rate at maturity $m$, denoted $R(m)$, can in turn be derived by integrating the equation (1) from zero to $m$ and dividing by $m$. That is

$$
R(m)=\frac{1}{m} \int_{s=0}^{m} r(s) d s,
$$

and the specific functional form employed in the estimation is as follows:

\footnotetext{
4 Given the possibility of time-varying risk premiums, we must be cautious in interpreting time-series movements of estimates.

5 The extended Nelson-Siegel model, shown in equation (1), adds the third term to the original one, thus allowing up to two hump- or U-shapes in the IFR curve, while the original one has only one humpor U-shape.
} 


$$
\begin{aligned}
R(m) & =\beta_{0}+\beta_{1} \cdot\left(\frac{\tau_{1}}{m}\right) \cdot\left(1-\exp \left(-\frac{m}{\tau_{1}}\right)\right) \\
& +\beta_{2} \cdot\left[\left(\frac{\tau_{1}}{m}\right) \cdot\left(1-\exp \left(-\frac{m}{\tau_{1}}\right)\right)-\exp \left(-\frac{m}{\tau_{1}}\right)\right] \\
& +\beta_{3} \cdot\left[\left(\frac{\tau_{2}}{m}\right) \cdot\left(1-\exp \left(-\frac{m}{\tau_{2}}\right)\right)-\exp \left(-\frac{m}{\tau_{2}}\right)\right] .
\end{aligned}
$$

The important features of equations (1) and (3) are that the limits of forward and spot rates when maturity approaches zero and infinity, respectively, are equal to $\beta_{0}+\beta_{1}$ and $\beta_{0}{ }^{6}$

\section{Indicators for the Policy Duration Effect}

We next define indicators for the policy duration effect by exploiting parameters for the extended Nelson-Siegel model. Figure 1 illustrates the indicators using the following parameter values: $\beta_{0}=2.8, \beta_{1}=-2.8, \beta_{2}=0.0, \beta_{3}=-6.0, \tau_{1}=0.3, \tau_{2}=1.0$. In this figure, the upper and lower thin curving lines indicate the IFR curve, $r(m)$, and the spot rate curve, $R(m)$, respectively. $r(m)$ starts from zero at maturity zero, manifests a twostage upward trend from the short end to mid-range, and finally converges to a longterm forward rate of $\beta_{0}$, shown as a dashed horizontal line close to the top.

In order to capture market expectations on the duration of the policy commitment as well as the policy impacts, we define four indicators for the policy duration effect below. First, we define the policy duration, denoted by $P D$, at the point $\tau_{2}$, where $r(m)$ becomes increasingly upward-trending in the second stage increase, typically at the year-to-settlement of around one year or more. As mentioned earlier, the fourth term in the right hand side of equation (1) takes a minimum value at this point. All the downward factors are exhausted at this point, since $\tau_{2}$ always take a larger value than $\tau_{1}$. In the figure, $P D$ is one year, indicated by the first dashed vertical line to the left. ${ }^{7}$

6 In our estimation, we exploit the first feature to keep the very short end of the IFR curve from becoming negative, by imposing the restriction that the overnight uncollateralized call rate be equal to $\beta_{0}+\beta_{1}$. This restriction is sufficient to prevent the zero-bound of nominal interest rates from influencing the estimates. We also use the second feature to compile an indicator for policy duration effect since it corresponds to the restriction that forward rates for settlements very far into the future be constant.

7 An alternative definition of $P D$ is possible, depending on how we define the end of the flattened zone before the second stage increase. For example, it could also be defined as the point at which the second derivative of $r(m)$, or acceleration of the speed of increase in $r(m)$, is locally maximized. Although the estimates based on our definition are somewhat greater than those based on the alternative definition, 
Second, we use the estimated spot rate at $P D, R(P D)$, as a measure of market confidence in the BOJ's policy commitment to a zero interest rate. ${ }^{8}$ This is because, as shown in equation (2), $R(P D)$ is equivalent to the lower area of the IFR curve from zero to $P D$. That is,

$$
R(P D)=\frac{1}{P D} \int_{s=0}^{P D} r(s) d s .
$$

In other words, $R(P D)$ is the averaged IFR between zero and $P D$. A smaller $R(P D)$ implies that financial market participants expect a lower path of short-term interest rates and have greater confidence in the BOJ's commitment to zero interest rates. In the figure, $R(P D)$ is approximately equal to 0.4 percent, shown as a dashed horizontal line close to the bottom. It is equivalent to the shaded area, or the integral of the IFR curve from zero to $P D$, divided by $P D$.

Third, we employ a slope of $r(m)$ at the inflection point as a proxy for the flatness of the whole shape of the curve. Due to the definition of the inflection point, this is the maximum grade of $r(m)$ in the second stage increase. $r(m)$ then gradually converges to the long-term forward rate, given by $\beta_{0}$. This slope is denoted $S L$. Given that the inflection point approximately corresponds to $2 * \tau_{2}$ in our specification, the slope at this point is:

$$
S L=\arctan \left(r^{\prime}\left(2 * \tau_{2}\right)\right) .
$$

In the figure, $2^{*} \tau_{2}$ is 2.0 years, depicted by the second dashed vertical line from the left. $S L$ is approximately 39.5 degrees.

Fourth, we use $\beta_{0}$, which corresponds to a long-term forward rate, or $L F R$, as a proxy for the summation of expected inflation and expected economic growth, or expected nominal economic growth. ${ }^{9}$ More precisely, the steady-state nominal interest rate $i^{*}$ is equal to the sum of the steady-state real interest rate $r^{*}$ and the steady-state

these two estimates show very similar movements over time, with a very high coefficient of correlation of 0.96. Our definition offers the advantage that we can easily compute standard errors for $P D$ as well as $R(P D)$ based on the closed form solution for $P D$.

8 As shown by Fujiki and Shiratsuka (2002), $r(m)$ is also affected by the liquidity concerns of financial institutions, especially at the time of large liquidity events, such as the Y2K problem and the introduction of the real time gross settlement system.

9 In examining the time-series movements of the long-term forward rate, we need to be careful to account for the possible effects of demand-supply conditions in financial markets with long-term maturity. 
rate of inflation $\pi^{*}$ by Fisher's equation. Thus, $L F R$ can be written as

$$
L F R=i^{*}+\rho=r^{*}+\pi^{*}+\rho,
$$

where $\rho$ is a risk premium. This is deemed to reflect market expectations for long-term economic performance.

Among the four indicators for the policy duration effect, it should be noted that the first two indicators look at the term structure of interest rates in the short term, tracing the expected initial impacts of policy actions. In contrast, the other two indicators focus on the term structure at the medium- to long-term to extract an indication of market expectations regarding future inflation and real interest rates, thereby indicating market assessments of those policy impacts.

\section{Empirical Evidence on the Policy Duration Effect}

In this section, we summarize empirical findings on the policy duration effect in Okina and Shiratsuka (2003). We first present the data used to estimate the IFR curve over time and provide the estimated results of the extended Nelson-Siegel model. In addition, we compute indicators for the policy duration effect, based on the estimation result for the IFR curve.

\section{A. Data}

We use data for euro-yen Tokyo interbank offered rates (TIBOR) as short-term interest rates, ranging from one- to twelve-month contracts, and yen swap rates as medium- to long-term interest rates from two- to twelve-year contracts. ${ }^{10}$ As mentioned earlier, we also use the overnight uncollateralized call rate to impose the restriction that the overnight call rate be equal to $\beta_{0}+\beta_{1}$. The sample period, which is determined by data availability, is every business day from March 2, 1998 to February 28, 2003.11

\footnotetext{
10 As pointed out in Shigemi et al. (2000) and Fukuta, Saito, and Takagi (2002), the pricing of Japanese government bonds (hereafter JGBs) crucially depends on their convenience, reflecting a difference in the characteristics of each issue, such as outstanding volume and coupon rate, as well as market liquidity. In particular, the pricing of JGBs in 1998-2000 was highly distorted by various problems in market liquidity, including the $\mathrm{Y} 2 \mathrm{~K}$ problem. It would thus be difficult to extract a unique yield curve as a benchmark from the market rates of JGBs, given the possible effects of the credit premium and other perturbing factors, such as macro-hedge accounting, on euro-yen TIBORs and swap rates.

11 Our sample period corresponds approximately to Governor Hayami's term of office (from March 20, 1998 to March 19, 2003). However, it should be noted that our sample period starts shortly before the
} 


\section{B. Estimated Results for the Nelson-Siegel Model}

Figure 2 , as indicated from the top to the bottom panels, respectively summarizes the estimated results of Okina and Shiratsuka (2003) for parameters $\beta_{0}, \beta_{1}, \beta_{2}, \beta_{3}, \tau_{1}$, and $\tau_{2}{ }^{12}$ In each panel, a solid line shows the estimated parameters. Shaded lines show the upper and lower bounds of the confidence interval for each parameter, obtained by adding and subtracting two times the standard errors of the estimated coefficient.

The magnitudes and signs of the estimated parameters are consistent with our assumptions for the typical shape of the IFR curve since 1998. For example, $\beta_{0}$ and $\beta_{1}$ typically range from 2 to 3 , and -3 to -2 , respectively, except for the periods of the JGB market boom in the fall of 1998 and in January 2003. $\beta_{2}$ deviates insignificantly from zero, except for the period when the IFR curve manifests a complex shape, such as the initial stage of the zero interest rate policy, and the end of a fiscal year or end of the reserve maintenance period when the overnight rate temporarily jumps. $\beta_{3}$ always takes a negative value, and has been stable, ranging from -6.0 to -3.5 , except in 1999, when it often had values less than -7.0. $\tau_{1}$ and $\tau_{2}$ always take positive values and were stable until 2000, rising gradually from the beginning of 2001.

Okina and Shiratsuka (2003) examine the robustness of estimation results against the zero-bound of nominal interest rates by using the trade date January 29, 2003 as an example, when $\beta_{0}$ or $L F R$ take a minimum value in the sample period. Figure 3 plots observed spot rates and estimated spot and instantaneous forward rates. The circles are observed spot rates for the overnight call rate, 12 euro-yen TIBORs, and 13 yen swap rates. The thin and bold lines indicate the estimated spot and instantaneous forward rates, respectively. The shaded lines associated with these two lines indicate their confidence intervals, computed using the delta method.

We can see from the figure that the parameters for the extended Nelson-Siegel model are a fairly precise estimation, and that the confidence intervals for the spot and instantaneous forward rates are very narrow. The figure apparently indicates that restricting the shortest end to equivalency to the overnight uncollateralized call rate is sufficient to keep the zero-bound of nominal interest rates from influencing the

launch of the ZIRP. Thus, it is difficult to compare the yield curve behavior under the ZIRP and the QME with those under a normal policy regime in which nominal short-term interest rates are well above zero.

12 Our estimations use the CML procedure in GAUSS 3.5. 
estimates, even under the recent low and flat yield curve.

\section{Estimated Indicators for Policy Duration Effect}

Okina and Shiratsuka (2003) compute indicators for the policy duration effect, based on the estimated results in the previous section, and assess the policy duration effect under the zero interest rate policy as well as quantitative monetary easing.

Figure 4 displays the computed results of the aforementioned indicators over time shown in Okina and Shiratsuka (2003): panel [1] represents the policy duration $(P D=$ $\left.\tau_{2}\right)$, panel [2] represents the estimated spot rate at $P D(R(P D))$, panel [3] represents the slope of the IFR curve at the inflection point $\left(S L=\arctan \left(r^{\prime}\left(2 * \tau_{2}\right)\right)\right)$, and panel [4] represents the long-term forward rate $\left(L F R=\beta_{0}\right)$. The figure also shows the confidence intervals for each indicator by shaded lines, obtained by adding and subtracting two times the standard errors for each indicator. ${ }^{13}$

Among the four indicators, $P D$ and $R(P D)$ look at the term structure of interest rates in the short horizon, tracing the expected initial impacts of policy actions. In contrast, $S L$ and $L F R$ focus on the term structure for the medium- to long-term to extract an indication of market expectations regarding future inflation and real interest rates, thereby deriving market assessments of those policy impacts.

Panel [1] of the figure shows that $P D$ has three upward trend phases: (i) the period soon after the launch of the zero interest rate policy, (ii) the period from the beginning of 2001 to June 2001, and (iii) the period from April 2002 to end of 2002. Among the three phases, the last phase exhibits more persistent but less rapid increases than do the previous two.

Panel [2] displays two major declines for $R(P D)$ : one for February to March 1999, and the other for early 2001. Both cases show significant declines of approximately 40 basis points in a month. The first decline is soon after the launch of the zero interest rate policy, while the second one is shortly before the launch of quantitative monetary easing, not after. In the latter case, a large part of the commitment effect appears in advance to making an explicit commitment.

Panel [3] shows that $S L$ declines significantly three times, each corresponding to the three rising phases of $P D$. The first decline, after the launch of the zero interest rate policy, led to a subsequent rebound, as business conditions recovered, especially after

13 We apply the delta method to compute standard errors for $R(P D)$ and $S L$. 
spring 2000. In contrast, the second decline did not appear to be accompanied by a significant rebound, and the third decline persists as of February 2003, which is the end of the sample period for our estimations.

Panel [4] demonstrates that $L F R$ has a general downward trend since 2000, with some cyclical ups and downs within this downward trend. Declines grow with passing time, while rebounds become weaker. Moreover, a major decline is observed following the beginning of 2003, reflecting prolonged deflationary expectations in the financial markets.

To sum up our empirical observations on the policy duration indicators in Okina and Shiratsuka (2003), ${ }^{14} P D$ generally increases over time, while the other three indicators, $R(P D), S L$ and $L F R$, decline. Increased $P D$ and declined $R(P D)$ indicate that the IFR curve in the short end becomes flatter, and declined $S L$ and $L F R$ imply that the IFR curve in the longer end levels off as well.

The above observation suggests two points. First, quantitative monetary easing within the sample period strengthened the policy duration effect, enhancing market credibility to the BOJ's commitment to zero interest rates. Second, in spite of such a policy duration effect, even though it was fairly strong, it largely failed to reverse market expectations that deflation and low economic growth would persist well into the future. Rather, the policy duration effect confined market expectations of prolonged deflation, thereby leading market participants to adjust to such a state of the economy. This in turn made it more difficult for the BOJ to reverse deflationary expectations.

If the policy duration effect is strong enough to alter market expectations regarding the future course of the economy in a positive direction, the slope of the IFR curve in the mid-range as well as the long-term forward rate are expected to increase. In addition, such positive expectations in turn shorten the expected duration of the policy commitment to a zero interest rate or quantitative monetary easing. On the other hand, if the policy duration effect is not sufficiently effective and expectations of deflation and low economic growth remain, the slope of the IFR curve in the mid-range and the long-term forward rate are unlikely to increase.

Quantitative monetary easing also reduces the incentive for financial institutions

\footnotetext{
14 In Okina and Shiratsuka (2003), we also carry out case study analyses to detect the impact of changes in monetary policy in the short run, which are of interest, but not shown here because of space constraints.
} 
to assume interest rate risks. As market expectations of a prolonged zero interest rate intensify, financial institutions are more likely to purchase JGBs with less concern for interest rate risks and potential capital losses. In fact, they are less likely to hedge their interest rate risks from a massive purchase of JGBs by swapping fixed rates in exchange for floating rates. As a result, the yen swap rate declined substantially from mid-1999, and the yen swap spread, defined as the difference between the yen swap rate and the JGB rate at the same maturity, has been reduced to below zero since the end of 2001, as shown in Figure 6. This observation implies that interbank markets not only for shortterm contracts but also for longer-term contracts have virtually ceased to function as a risk-sharing device among financial institutions and are insensitive to interest risks.

\section{Wavelet Analysis on Indicators for Policy Duration Effect}

In this section, we apply the wavelet analysis to indicators for policy duration effect, and examine policy duration effect to reinforce our findings in Okina and Shiratsuka (2003).

\section{A. Policy Duration Effect and Wavelet Analysis}

A wavelet is a small wave, and wavelet analysis expresses a time series as a sum of localized small and temporary waves. This technique enables us to decompose a time series into both frequency domain and time domain simultaneously. As a result, it has an advantage in analyzing data that show irregular fluctuations as well as time-varying frequency characteristics.

In contrast, Fourier analysis, often used in analyzing frequency characteristics of time series data, decompose a time series into a sum of sine and cosine functions at different wavelengths. Fourier analysis, however, has a limitation in that it is unable to capture time-varying frequency characteristics, if any, because information on time domain is lost.

As we can see from the empirical evidence of Okina and Shiratsuka (2003) summarized above, it is important to note the time-varying nature of policy impacts under the zero interest rate policy and quantitative monetary easing. Such a timevarying nature comes from two elements: one is the accumulation of experience on the part of market participants, and the other is a change in financial and macroeconomic environments. Given this, it seems interesting to examine policy duration effect from 
the viewpoint of how frequency characteristics of indicators for policy duration effect evolved. Such an analysis serves to strengthen our empirical results in Okina and Shiratsuka (2003).

\section{B. Wavelet Analysis on Indicators for Policy Duration Effect}

We apply wavelet analysis to the four indicators for policy duration effect (Figure 5). ${ }^{15}$ In this figure, we decompose indicators for policy duration effect into six components: a low-frequency component (wavelet smooth at level 5) and five higher-frequency components (wavelet details at levels 1 to 5). Specifically, the wavelet smooth at level 5 , shown in the top panel, captures a trend component by removing cyclical components up to the frequency of $2^{5}$ or one and half months. The wavelet details at levels 1 through 5, shown from the second top panel to the bottom panel, indicate a stationary component with the frequency of two, four, eight, 16, and 32 business days, respectively.

The estimation period for wavelet analysis is from March 24, 1998 to February 28, 2003. This is slightly shorter than the sample period of our data set, because wavelet decomposition up to level 5 requires a sample size that is a multiple of $2^{5}=32$. We set the end of the estimation period as the end of our data set, and then decide the beginning of the estimation period retroactively so that the sample size is equal to 1,216 , which is the greatest multiple of 32 within our data set.

$P D$ in Figure 5[1] exhibits three phases of upward trending. During the first two phases, that is, soon after the launch of the zero interest rate policy and before and after the launch of quantitative monetary easing, the volatility at levels 1 to 3 with higher frequency increases. In contrast, during the third phase, the volatility of higher frequency fluctuations remains stable. This suggests that market expectations with respect to prolonging policy duration were formed in an extremely smooth manner during the third phase.

$R(P D)$ in Figure 5[2] shows declines in the whole range of cyclical components from levels 1 to 5 since the launch of the zero interest rate policy. This is particularly true for the period from late 2001 to early 2003. In addition, the wavelet smooth at

\footnotetext{
15 We choose the Daubechies (10) wavelet, $D(10)$, by comparing wavelet filters with a certain length of support in order to extract trend fluctuations of policy duration indicators. See Appendix 2 for a brief summary of wavelet analysis.
} 
level 5 declines markedly. These observations reveal that market credibility to the BOJ's commitment to a zero interest rate was enhanced, and was stabilized at a high level during the period of quantitative monetary easing.

$S L$ in Figure 5[3] is characterized by the stabilization of the whole range of cyclical components especially since 2002. These observations offer the possibility that the yield curve in the mid-range became fairly stable in a smooth manner during the aforementioned third phase of upward trending in $P D$. In other words, this implies that the policy duration effect functioned as an anchor for yield curve formation in the midrange.

LFR in Figure 5[4] shows the stabilization of cyclical components at all levels in 2002, suggesting that market expectations on long-term interest rates were stably formed. Especially, a decline in volatility of wavelet detail at level 5 suggests the possibility that deflationary expectations became increasingly confined.

The above observations suggest two points, which are consistent with the empirical evidence in Okina and Shiratsuka (2003). First, quantitative monetary easing within the sample period strengthened the policy duration effect, enhancing the market credibility to the BOJ's commitment to a zero interest rate. Second, in spite of such a policy duration effect, even though it was fairly strong, it largely failed to reverse market expectations that deflation and low economic growth would persist well into the future. Rather, the policy duration effect confined market expectations of prolonged deflation, thereby leading market participants to adjust to such a state of the economy. This in turn made it more difficult for the BOJ to reverse deflationary expectations.

\section{Concluding Remarks}

In this paper, we have examined the policy commitment effect, or policy duration effect, of recent monetary policy in Japan, which has been characterized by the unusual environment of zero nominal short-term interest rates. To do so, we first reviewed the analytical framework and results of Okina and Shiratsuka (2003), and then we introduced wavelet analysis to four indicators of policy duration effects.

Wavelet analysis in this paper confirmed the conclusions of Okina and Shiratsuka (2003). First, the policy duration effect was very effective in stabilizing market expectations for the path of short-term interest rates, lowering longer-term interest rates and flattening the yield curve. In fact, this policy has played a certain role in bolstering 
Japan's economy, such as contributing to stabilizing the financial system. Second, however, expectations of prolonged deflation are most typically signaled by lowered long-term interest rates, indicating financial market expectations that deflation will persist for years, rather than rapidly reversing.

\section{Appendix 1. An Illustration of the Contributions of Each Component in the Nelson-Siegel Model}

In Appendix 1, we provide an intuitive account of the estimates for the extended Nelson-Siegel model.

Figure A-1 plots hypothetical IFR curves for the extended version of the NelsonSiegel model with the following parameters: $\beta_{0}=2.8, \beta_{1}=-2.8, \beta_{2}=0.0, \beta_{3}=-6.0, \tau_{1}$ $=0.3, \tau_{2}=1.0$ for the upper panel, and $\beta_{0}=2.8, \beta_{1}=-2.3, \beta_{2}=-1.0, \beta_{3}=-6.0, \tau_{1}=0.3$, $\tau_{2}=1.0$ for the lower panel. The parameters are common except for $\beta_{1}$ and $\beta_{2}$. These parameters are chosen because they represent typical shapes of the IFR curve under a zero interest rate policy and quantitative monetary easing. The upper panel illustrates the most typical shape of the IFR curve. The lower panel corresponds to a situation wherein the overnight rate temporarily jumps at the end of the calendar year, the fiscal year, or the reserve maintenance period. ${ }^{16}$

This figure also shows the contributions of each term. The first and fourth terms occur in both panels since the same parameters except for $\beta_{1}$ and $\beta_{2}$ are used. The first term, $\beta_{0}$, is constant over the whole range of time-to-settlement. The second term $\beta_{1} * \exp \left(-m / \tau_{1}\right)$ is an exponential function, exhibiting an upward trend in the short end of the IFR curve when $\beta_{1}$ is negative. This impact decays gradually (quickly) as $\tau_{1}$ becomes larger (smaller). The third term in the lower panel, $\beta_{2} *\left(-m / \tau_{1}\right) * \exp \left(-m / \tau_{1}\right)$, creates a U-shape in the short-term since $\beta_{2}$ is negative.

The fourth term, $\beta_{3} *\left(-m / \tau_{2}\right) * \exp \left(-m / \tau_{2}\right)$, also adds a U-shape since $\beta_{3}$ is negative (a hump shape when positive). This term allows a non-monotonic increase in the IFR

\footnotetext{
$16 r(0)$, which is equal to $\beta_{0}+\beta_{1}$, is supposed to be zero under the zero interest rate policy as well as quantitative monetary easing, as shown in the upper panel, while $r(0)$ in the lower panel, which is also equal to $\beta_{0}+\beta_{1}$, is significantly higher than zero. Since $\beta_{0}$ is equal to the limits of forward and spot rates when maturity approaches infinity, this parameter is common to both panels. Therefore, the absolute value of $\beta_{1}$ must take a different value from that of $\beta_{0}$ when the overnight rate temporarily jumps.
} 
curve. In addition, this U-shape decays slower than that of the third term because $\tau_{2}$ is larger than $\tau_{1}$. A large (small) value of $\tau_{2}$ means that the effects decay more slowly (quickly), and the IFR converges to the long-term forward rate more slowly (quickly).

Since $\beta_{3}$ is negative, the fourth term creates a U-shape, taking a minimum at $\tau_{2}$ and an inflection point at $2 * \tau_{2}$. Moreover, the point of $2 * \tau_{2}$ approximately corresponds to the inflection point for the overall IFR curve since the second and the fourth terms almost converge to zero at the point of $2 * \tau_{2}$. Therefore, at this point, $r^{\prime}(m)$ is approximately locally maximized and $r^{\prime \prime}(m)$ is approximately zero.

\section{Appendix 2. A Basic Framework of Wavelet Analysis}

In Appendix 2, we offer a brief exposition of wavelet analysis by focusing on the basic framework of discrete wavelet transform. See Schleicher (2002), for example, for details on wavelets for applications to economic analysis.

\section{A. Wavelet Filter}

Wavelet analysis can be viewed as a kind of linear filtering. Wavelet filter $h$ is defined so as to satisfy the conditions below:

$$
\sum_{k=1}^{L} h_{k}=0, \quad \sum_{k=1}^{L} h_{k}^{2}=1, \quad \sum_{k=1}^{L} h_{k} h_{k+2 n}=0, \quad(n \text { is a non-zero integer })
$$

where $L$ denotes the length of filter or support. The first condition implies that the filter is a high-pass filter that captures cyclical fluctuations and extracts high frequency components. The second condition is for standardization. The third condition means that filters are orthogonal to each other with respect to a shift of even numbers.

Scaling filter $g$, which is twin to the wavelet filter, is defined so as to satisfy the quadrature mirror relationship below:

$$
\left.g_{i}=(-1)^{i} h_{L-i+1} \Leftrightarrow h_{i}=(-1)^{i-1} g_{L-i+1} \text { (4ii = (a2, }, \ldots, L\right) \text {. }
$$

Given the above relationship, a scaling filter is shown to meet the conditions below:

$$
\sum_{k=1}^{L} g_{k}=\sqrt{2}, \quad \sum_{k=1}^{L} g_{k}^{2}=1, \quad \sum_{k=1}^{L} g_{k} g_{k+2 n}=0 . \quad(n \text { is a non-zero integer })
$$

The first condition implies that the scaling filter is a low-pass filter to extract low frequency components. The second and third conditions are respectively for standardization and orthogonality, which are the same as for the wavelet filter. Then, we have 


$$
\sum_{k=1}^{L} g_{k} h_{k+2 n}=0, \quad(n \text { is a non-zero integer })
$$

which implies that the wavelet filter and scaling filter are orthogonal to each other with respect to a shift of even numbers.

The family of Daubechies wavelets is one of the often-used wavelets. Let $D(L)$ denote the Daubechies wavelet with support $L$ ( $L$ is an even number), then $D(L)$ is defined so as to simultaneously satisfy the equation (A-1) as well as the set of equations $(L / 2-1)$ below:

$$
\sum_{k=1}^{L}(k-1)^{i} h_{k}=0 . \quad i=1,2, \ldots, L / 2-1
$$

For example, the Daubechies wavelets with the support of 10 , or $D(10)$, is yielded from a set of equations (A-5) by setting $i=4$.

\section{B. Wavelet Transform}

The process of decomposing a time series into the time and frequency domains by using a wavelet filter is referred as wavelet transform. This process yields wavelet coefficients and scaling coefficients. In reverse, the process of reproducing the original time series from wavelet and scaling coefficients is referred to as inverse wavelet transform.

Now, let $x$ be a sequence of the time series, and suppose the length of time series is $N$. Let $w_{i}$ and $v_{i}$ denote the wavelet coefficient and scaling coefficient at level $i$. In addition, let us define the scaling coefficient at level 0 as being equal to the time series data, and $v_{0}=x$. When we apply the wavelet filter $h$ with support $L$ to the scaling coefficient at level $i-1, v_{i-1}$, we obtain the wavelet coefficient at level $I, w_{i}$, from the equation below:

$$
w_{i, t}=\sum_{k=1}^{L} h_{k} v_{i-1,\left\{(2 t-k) \bmod N / 2^{i-1}\right\}+1} .
$$

Here, $A \bmod B$ is the operator that divides $\mathrm{A}$ by $\mathrm{B}$ and returns only the remainder, thus producing an integer ranging from zero to $B-1$. Similarly, when we apply the scaling filter $g$ with support $L$ to the scaling coefficient at level $i-1, v_{i}-1$, we obtain the scaling coefficient at level $i, w_{i}$, from the equation below:

$$
v_{i, t}=\sum_{k=1}^{L} g_{k} v_{i-1,\left\{(2 t-k) \bmod N / 2^{i-1}\right\}+1} .
$$


What should be noted here is that the downsampling operation proceeds by every second data point. A process of filtering reduces computed wavelet and scaling coefficients by halves. However, the sum of the two coefficients is equal to the original time series, and no information is lost through filtering.

Since wavelet transform preserves all information contained by the original time series, the original series can be reproduced from the computed wavelet and scaling coefficients. This process is called inverse wavelet transform.

The process of reproducing the scaling coefficient at level $i, v_{i}$, from the wavelet coefficient at level $i+1, w_{i+1}$, and the scaling coefficient at level $i+1, v_{i+1}$, is given below.

First, upsampling is implemented to increase the reduced number of data at level $i+1$ by downsampling by inserting zeros between samples. Precisely, upsampled sequences of wavelet and scaling coefficients at level $i+1$, that is $w^{0}{ }_{i+1}=\left(0, w_{i+1,1}, 0\right.$, $\left.w_{i+1,2}, \ldots, 0, w_{i+1, N / 2}{ }^{i+1}\right)$ and $v_{i+1}^{0}=\left(0, v_{i+1,1}, 0, v_{i+1,2}, \ldots, 0, v_{i+1, N / 2}{ }^{i+1}\right)$, is made.

Next, the wavelet and scaling filters are applied to the upsampled wavelet and scaling coefficients, and by summing up this result, the scaling coefficient at level $i$ is obtained. That is

$$
v_{i, t}=\sum_{k=1}^{L} h_{k} w_{i+1,\left\{(t+k-2) \bmod N / 2^{i}\right\}+1}^{0}+\sum_{k=1}^{L} g_{k} v_{i+1,\left\{(t+k-2) \bmod N / 2^{i}\right\}+1}^{0} .
$$

\section{Multiresolution Analysis}

Finally, we review multiresolution analysis. Wavelet detail and wavelet smooth are the basic concepts in this analysis. Wavelet detail and smooth at level $i$ respectively capture cyclical components with the frequency of $2^{i}$ and trend components after removing the cyclical components up to the frequency of $2^{i}$.

Suppose that some levels of wavelet coefficients and scaling coefficients are obtained from the original time series by implementing wavelet transform. Then wavelet detail at level $i$, with the same length of time series as the original time series, is obtained by implementing inverse wavelet transform while replacing all wavelet and scaling coefficients being equal to zero except for the wavelet coefficient at level $i w_{i}$. Similarly, wavelet smooth at level $i s_{i}$ is obtained by implementing inverse wavelet transform $v_{i}$.

When we define $s_{0}=x$, the following equation holds:

$$
s_{i-1}=d_{i}+s_{i} .
$$


And, when we define wavelet rough as $r_{i}=\Sigma_{k=1}^{i} d_{k}$, the following equation holds:

$$
x=r_{i}+s_{i} .
$$

\section{References}

Eggertsson, Gauti B., and Michael Woodford, "The Zero Interest-Rate Bound and Optimal Monetary Policy," mimeo, 2003.

Fujiki, Hiroshi, Kunio Okina, and Shigenori Shiratsuka, "Monetary Policy under Zero Interest Rate --- Viewpoints of Central Bank Economists ---," Monetary and Economic Studies, 19 (1), Institute for Monetary and Economic Studies, Bank of Japan, 2001, pp. 89-130.

, and Shigenori Shiratsuka, "Policy Duration Effect under the Zero Interest Rate Policy in 1999-2000: Evidence from Japan's Money Market Data," Monetary and Economic Studies, 20 (1), Institute for Monetary and Economic Studies, Bank of Japan, 2002, pp. 1-31.

Fukuta, Yuichi, Makoto Saito, and Shingo Takagi, "Kokusai no Kakaku Keisei to Konbiniansu: 1990-nendai Kouhan no Nihon Kokusai no Keesu (Pricing of Government Bonds and their Convenience: A Case from the Japanese Government Bonds in the late 1990s)," Makoto Saito and Noriyuki Yanagawa eds., Ryudo-sei no Keizai-gaku (Economics of Liquidity), 2002, pp. 209-224 (in Japanese).

Goodfriend, Marvin, "Using the Term Structure of Interest Rates for Monetary Policy," Federal Reserve Bank of Richmond, Economic Quarterly, 84 (3), pp. 13-30, 1998.

Jung, Taehum, Yuki Teranishi, and Tsutomu Watanabe, "Zero Interest Rate Policy as Optimal Central Bank Commitment," mimeo, 2001.

Kimura, Takeshi, Hiroshi Kobayashi, Jun Muranaga, and Hiroshi Ugai, “The Effect of the Increase in Monetary Base on Japan's Economy at Zero Interest Rates: An Empirical Analysis," IMES Discussion Paper, No. 2002-E-22, Institute for Monetary and Economic Studies, Bank of Japan, 2002.

Marumo, Kohei, Takashi Nakayama, Shinichi Nishioka, and Toshihiro Yoshida, "Zero Kinri Seisaku-ka ni okeru Kinri no Kikan Kozo Moderu (A Term Structure Model of Interest Rates under Zero Interest Rate Policy)," Financial Markets Department 
Working Paper No. 2003-J-1, Financial Markets Department, Bank of Japan, 2003 (in Japanese).

Nelson, Charles R., and Andrew F. Siegel, "Parsimonious Modeling of Yield Curves," Journal of Business, 60 (4), 1987, pp. 473-489.

Okina, Kunio, and Shigenori Shiratsuka, "Policy Commitment and Expectation Formations: Japan's Experience under Zero Interest Rates," IMES Discussion Paper No. 2003-E-5, Institute for Monetary and Economic Studies, Bank of Japan, 2003.

Reifschneider, David, and John C. Williams, "Three Lessons for Monetary Policy in a Low-Inflation Era," Journal of Money, Credit and Banking, 32 (4), 2000, pp. 936966.

Shigemi, Yosuke, Sotaro Kato, Yutaka Soejima, and Tokiko Shimizu, "Honpo Kokusai Shijo niokeru Shijo Sankasha Koudou to Kakaku Kettei Mekanizumu: 1998 nenmatsu kara 1999 nen-chu no Shijo no Ugoki wo Rikai Suru tameni (Market Participants' Behavior and Pricing Mechanism of Japanese Government Bond Markets: An Interpretation of the Market Behavior from the end-1998 to 1999)," Kin'yu Kenkyu, 19 (S-2), Institute for Monetary and Economic Studies, Bank of Japan, 2002, pp. 145-184 (in Japanese).

Schleicher, Christoph, "An Introduction to Wavelets for Economists," Working Paper 2002-3, Bank of Canada, 2002.

Söderlind, Paul, and Lars E. O. Svensson "New Techniques to Extract Market Expectations from Financial Instruments," Journal of Monetary Economics 1997 (40), pp. 383-429. 
Figure 1. Indicators for the Policy Duration Effect (Illustration)

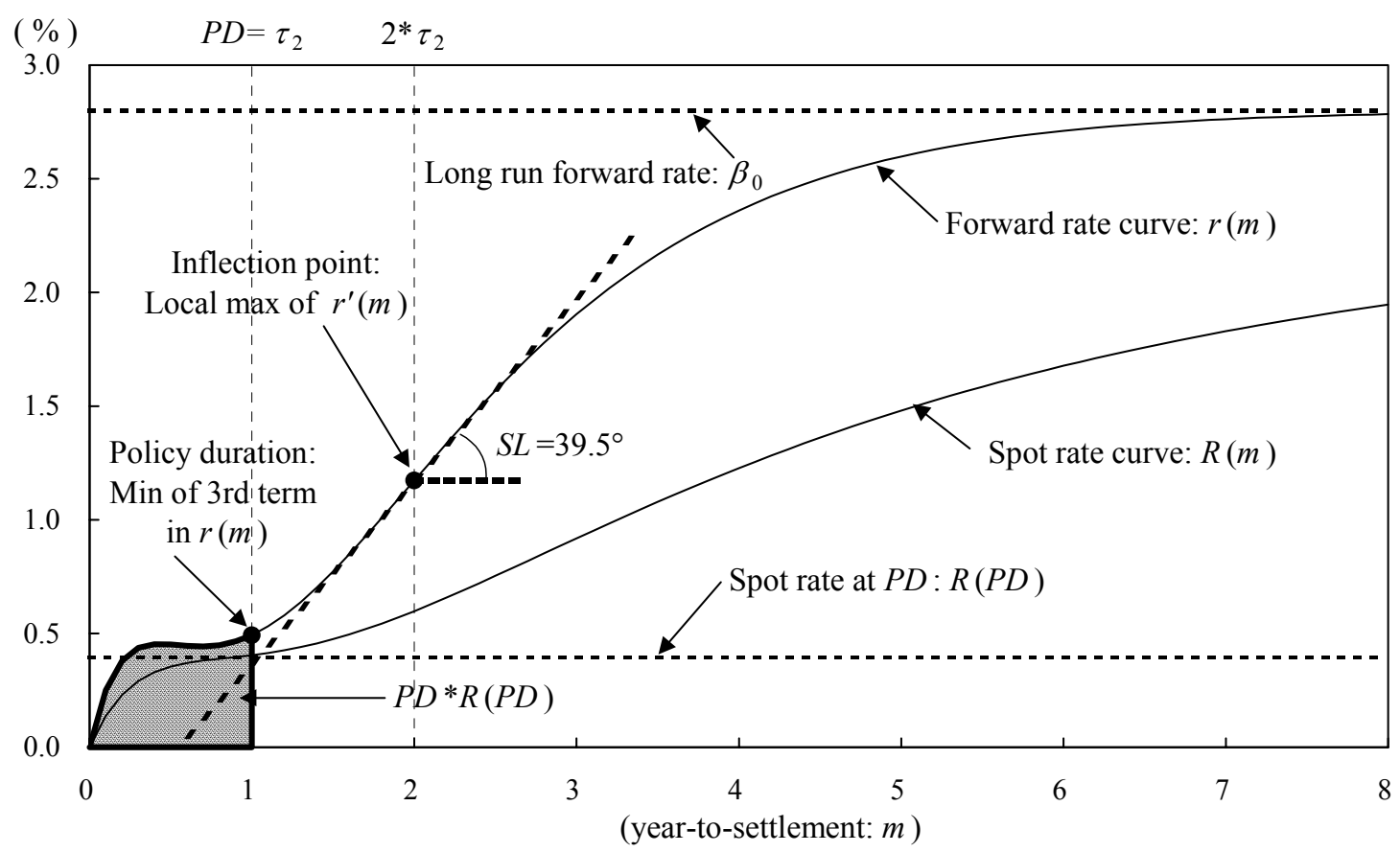

Notes: Forward rate and spot rate curves are computed by equations (1) and (3), respectively, using the following parameter values: $\beta_{0}=2.8, \beta_{1}=-2.8, \beta_{2}=0.0, \beta_{3}=-6.0, \tau_{1}=0.3, \tau_{2}=1.0$. 
Figure 2. Estimated Coefficients for NS Model
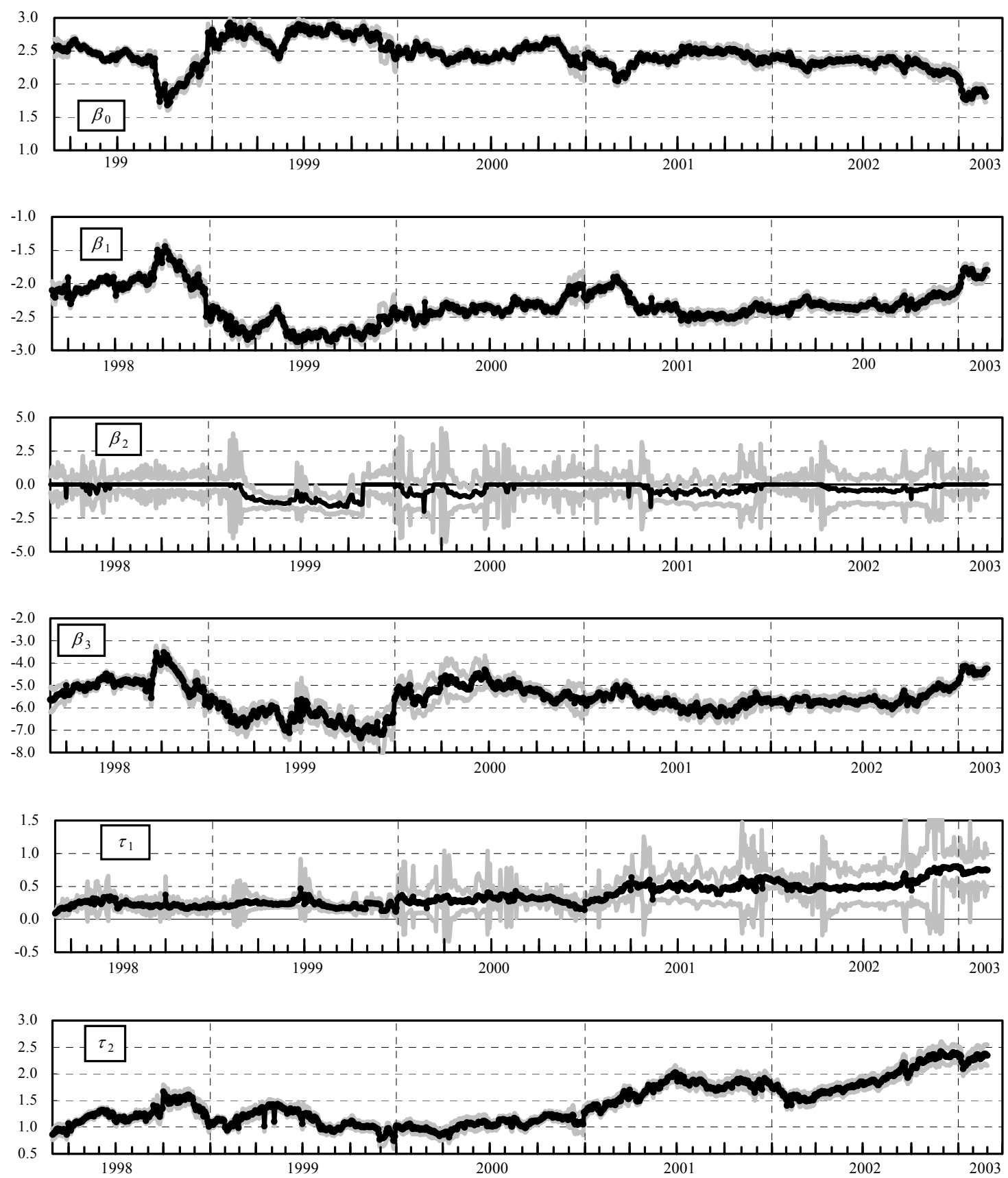

Note: 1. Bold lines are estimated coefficients, and shaded lines indicate their upper and lower bounds, respectively, of the confidence interval (estimated coefficients $\pm 2 *$ standard errors). 2. The solid and dotted vertical lines, respectively, indicate the year-end and quarter-end. 
Figure 3. Estimation Results for January 29, 2003

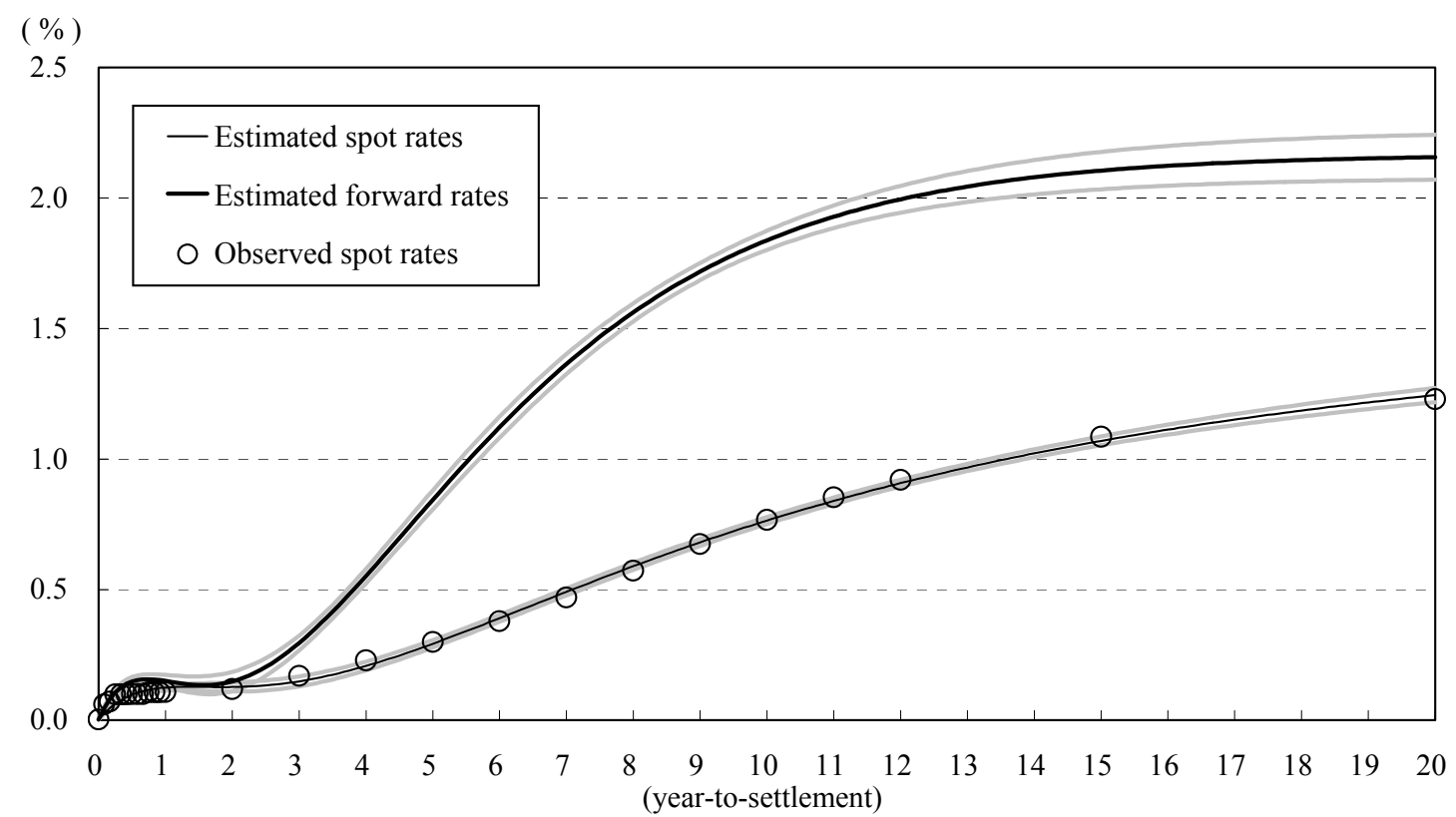

Note: The circles are observed spot rates for the overnight call rate, 12 euro yen TIBORs, and 13 yen swap rates. The thin and bold lines show the estimated spot rates and instantaneous forward rates, respectively. The shaded lines associated with these two lines indicate their confidence intervals. The estimates of parameter values are as follows: $\beta_{0}=1.787$ (s.e. $=$ $0.036), \beta_{1}=-1.785$ (s.e. $=0.036$ ), $\beta_{2}=-0.000$ (s.e. $\left.=0.170\right), \beta_{3}=-4.221$ (s.e. $=0.083$ ), $\tau_{1}=0.720($ s.e. $=0.079)$, and $\tau_{2}=2.266($ s.e. $=0.073)$. 
Figure 4. The Policy Duration Effect

[1] Policy duration: $P D$

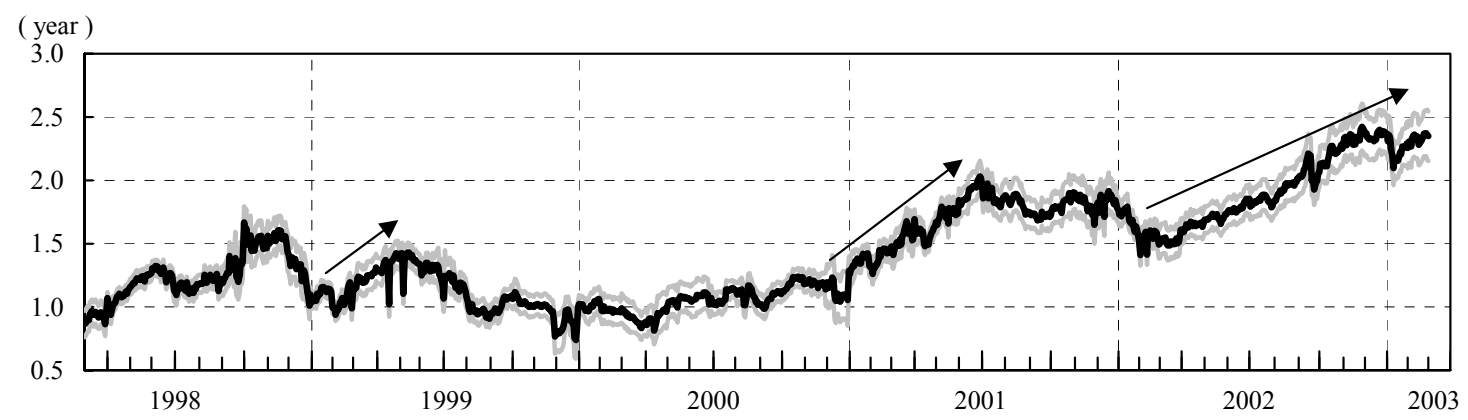

[2] Estimated spot rate at policy duration: $R(P D)$

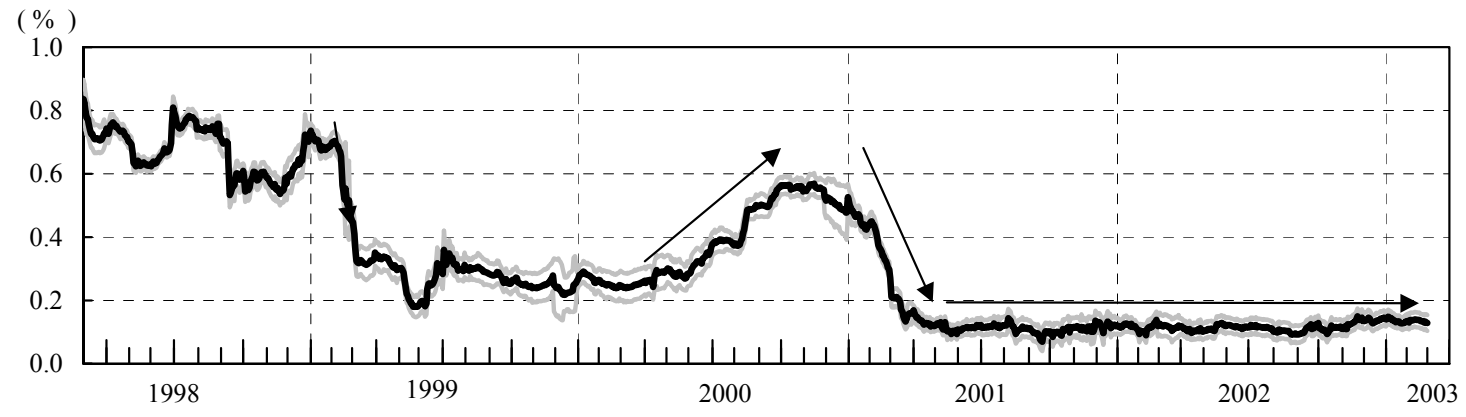

[3] Slope of forward rate curve at inflection point: $S L$

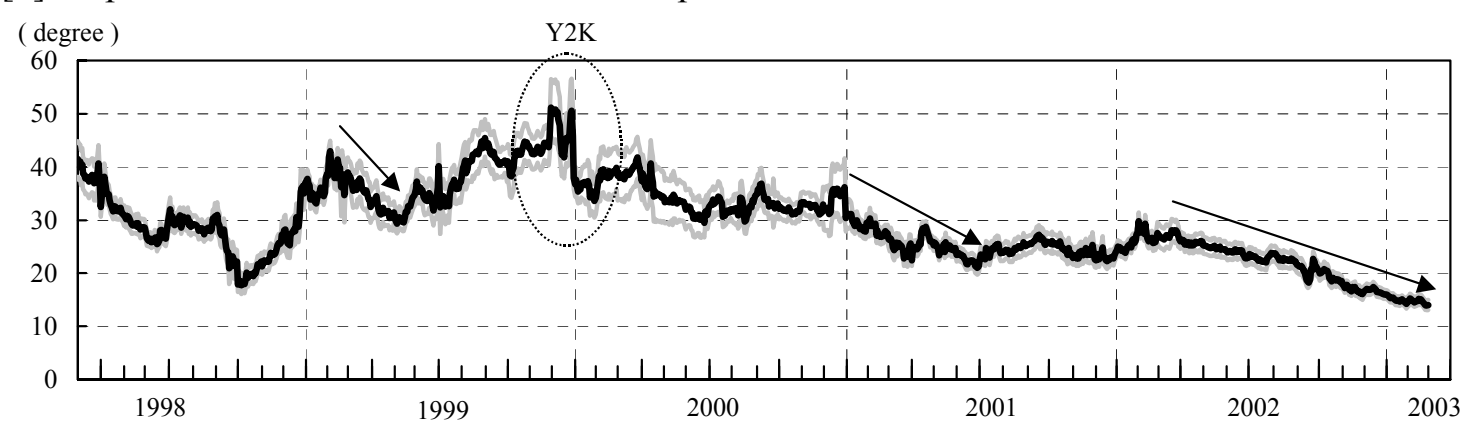

[4] Estimated long-term forward rate: $L F R$

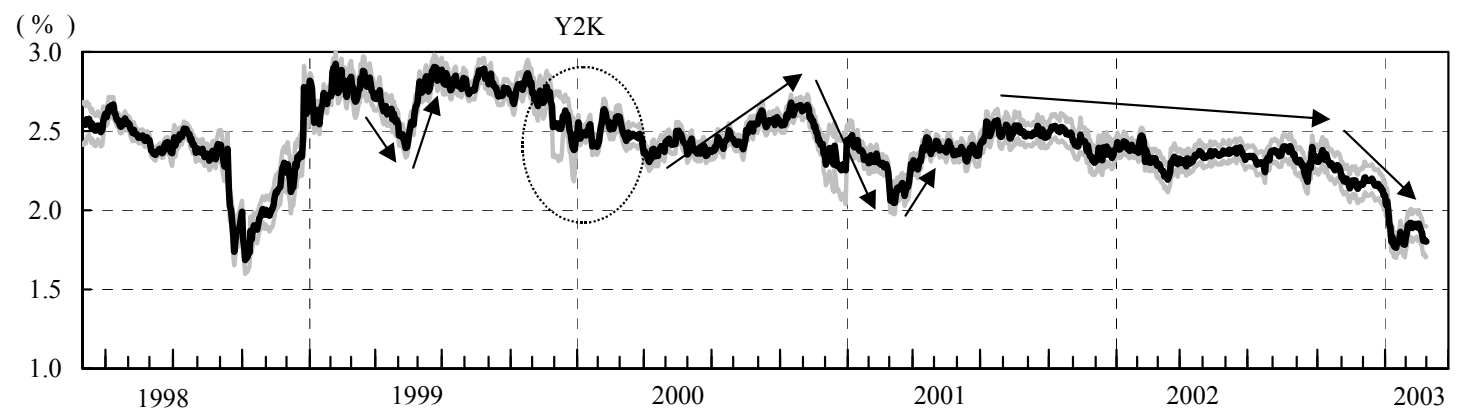

Note: The solid and dotted vertical lines, respectively, indicate the year-end and quarter-end. 
Figure 5. Wavelet Transform of Indicators for Policy Duration Effect

[1] Policy duration: $P D$
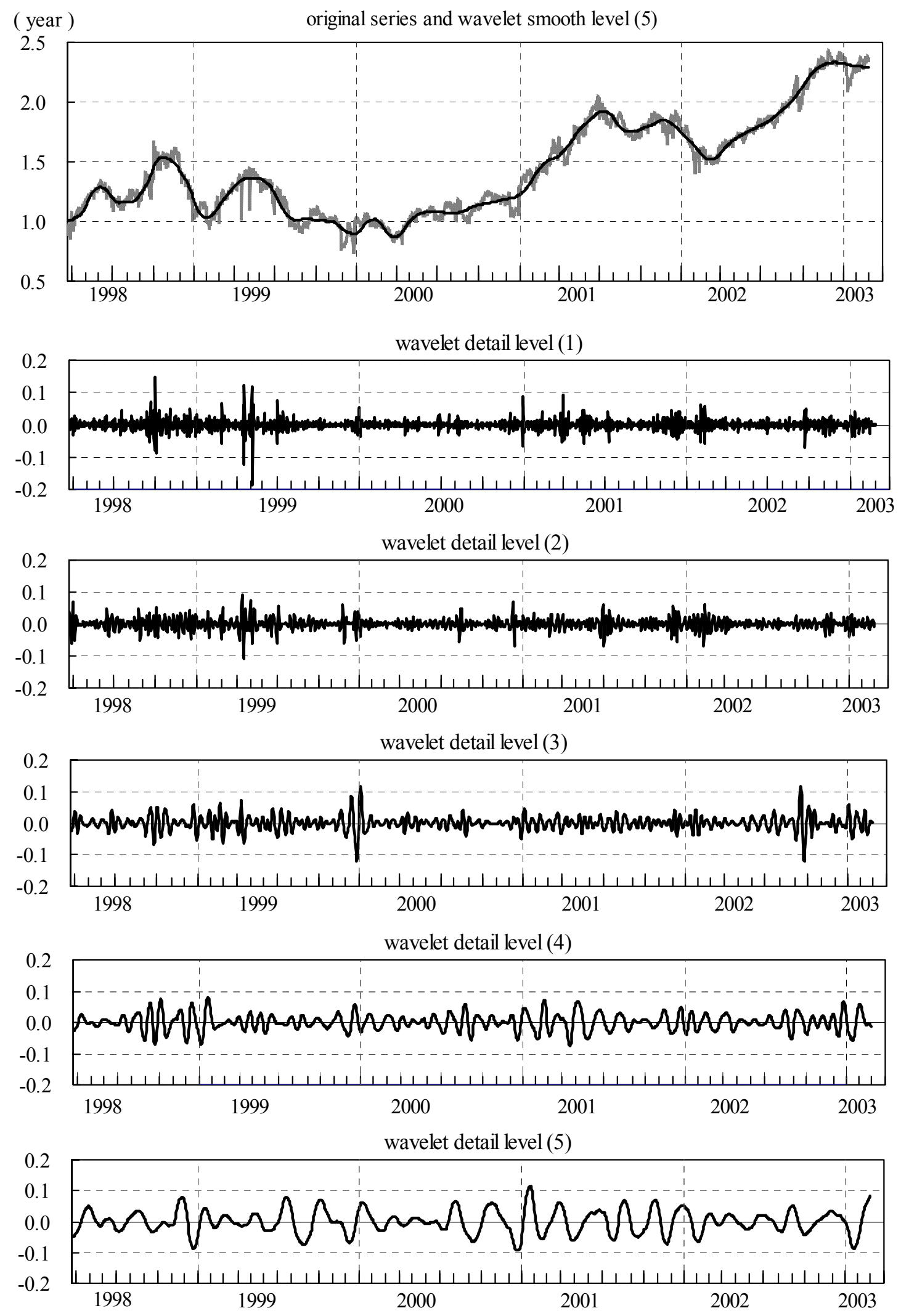
Figure 5 (continued)

[2] Estimated spot rate at policy duration: $R(P D)$

(\%)

original series and wavelet smooth level (5)
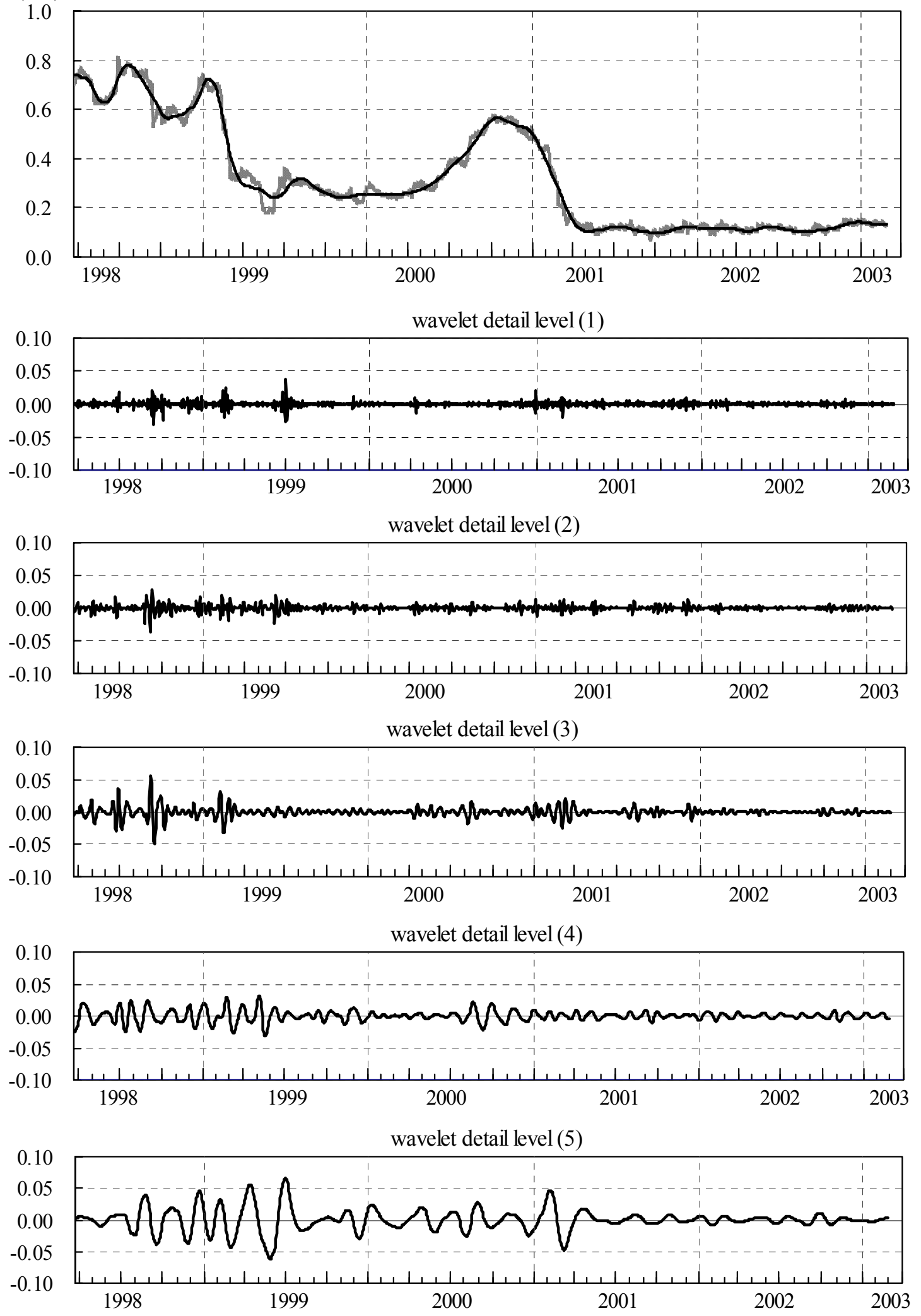
Figure 5 (continued)

[3] Slope of forward rate curve at inflection point: $S L$

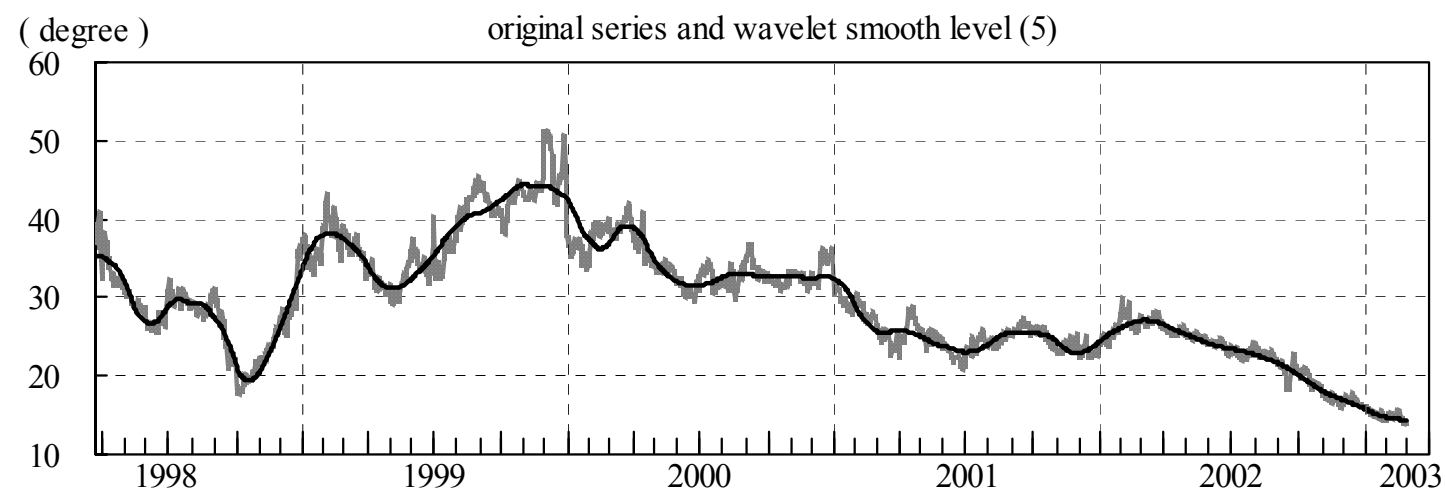

wavelet detail level (1)

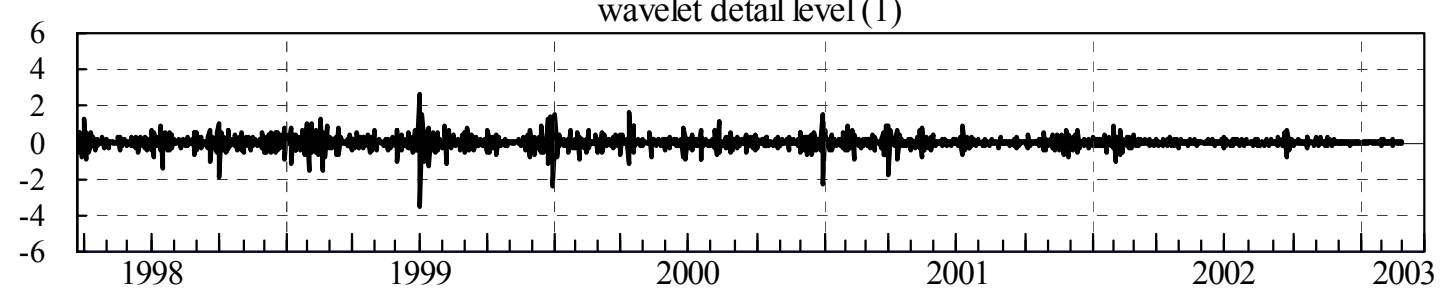

wavelet detail level (2)

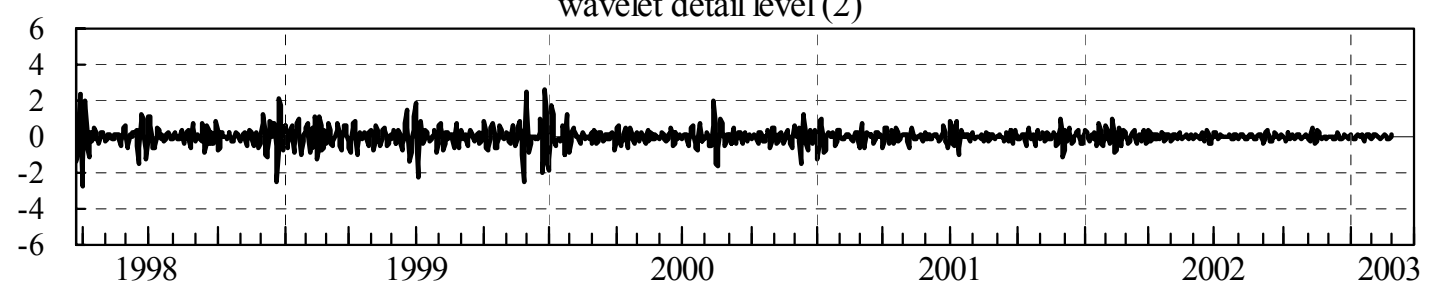

wavelet detail level (3)

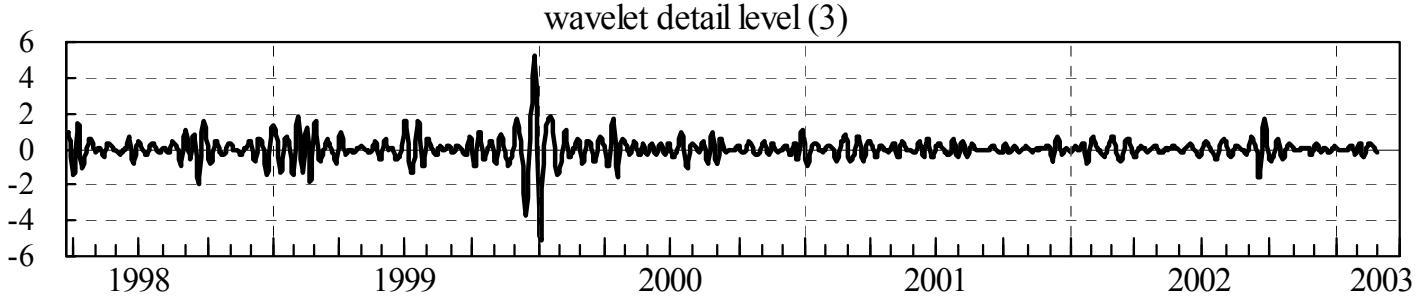

wavelet detail level (4)

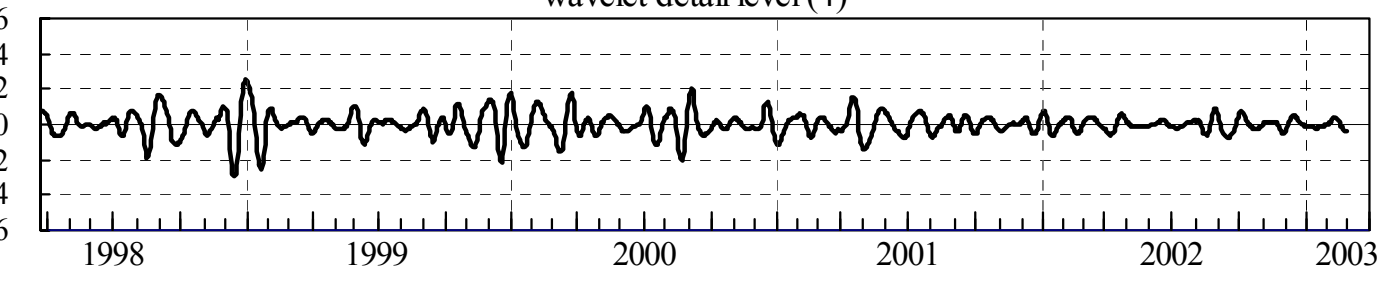

wavelet detail level(5)

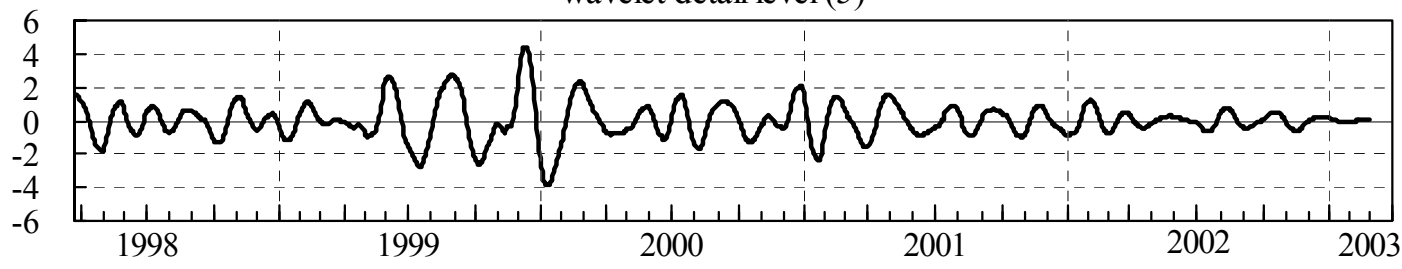


Figure 5 (continued)

[4] Estimated long-term forward rate: $L F R$
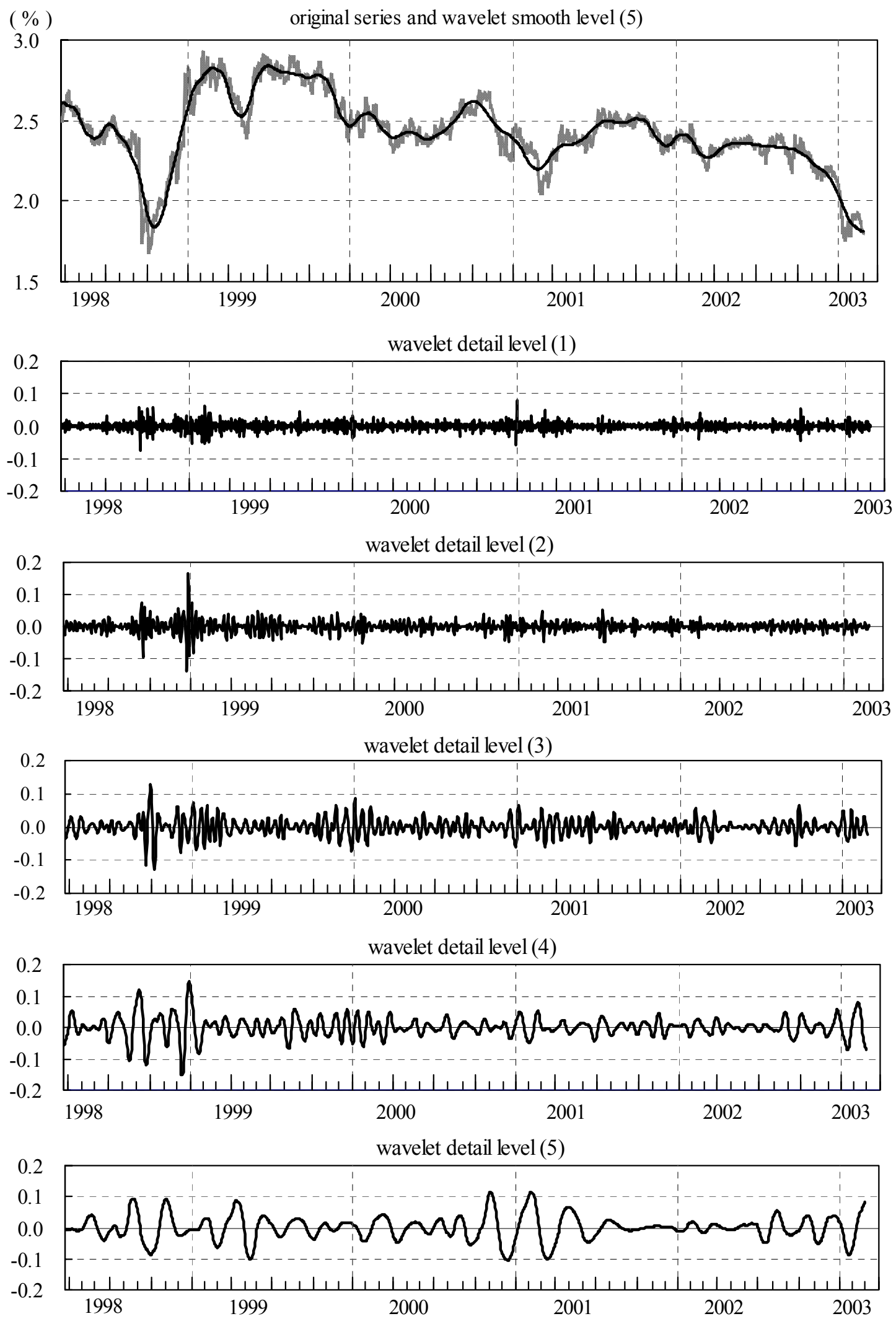
Figure 6. Yen Swap Spreads

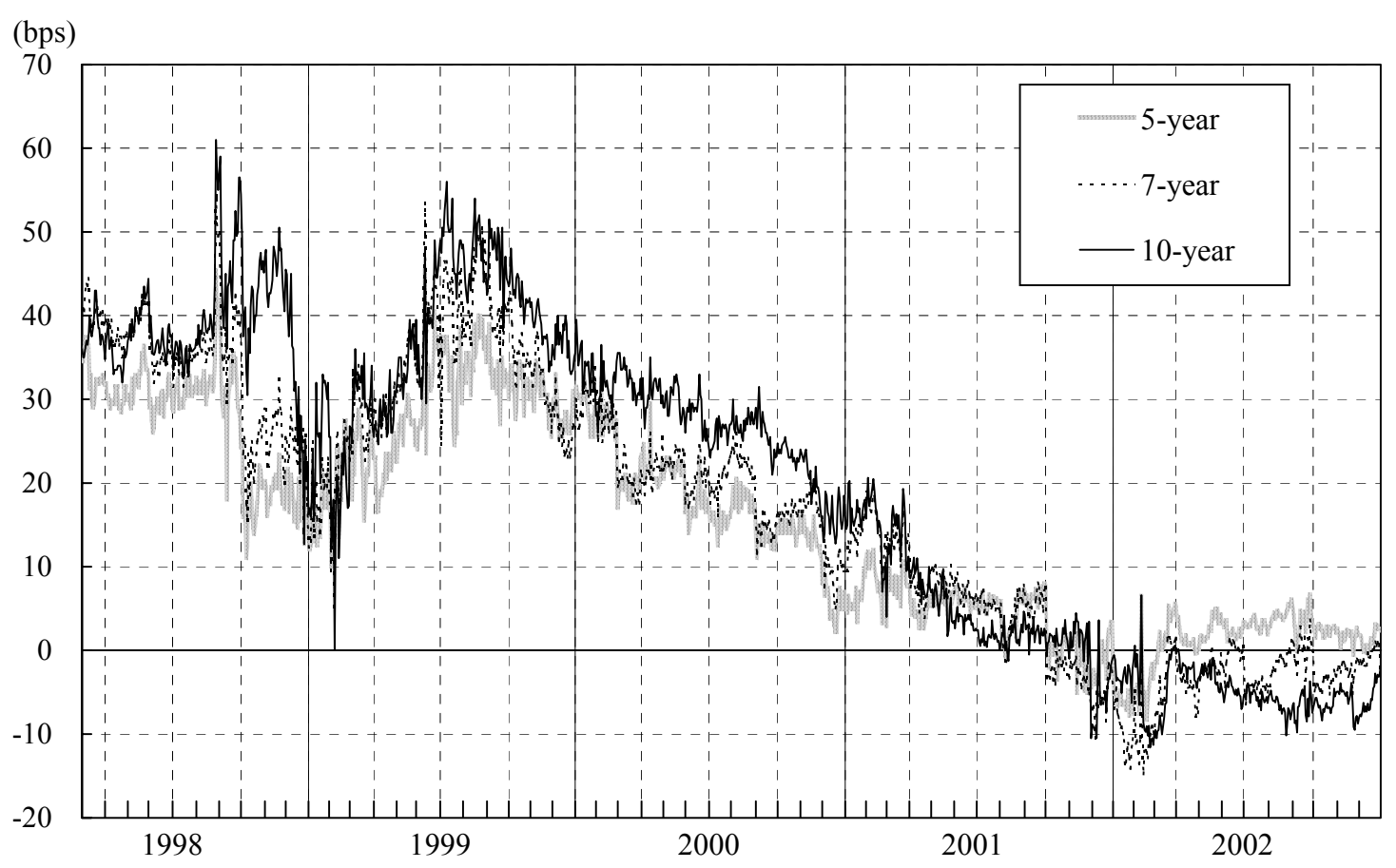

Source: Bloomberg. 
Figure A-1. Illustrated IFR Curve

[A] A typical shape under a zero interest rate policy and quantitative monetary easing

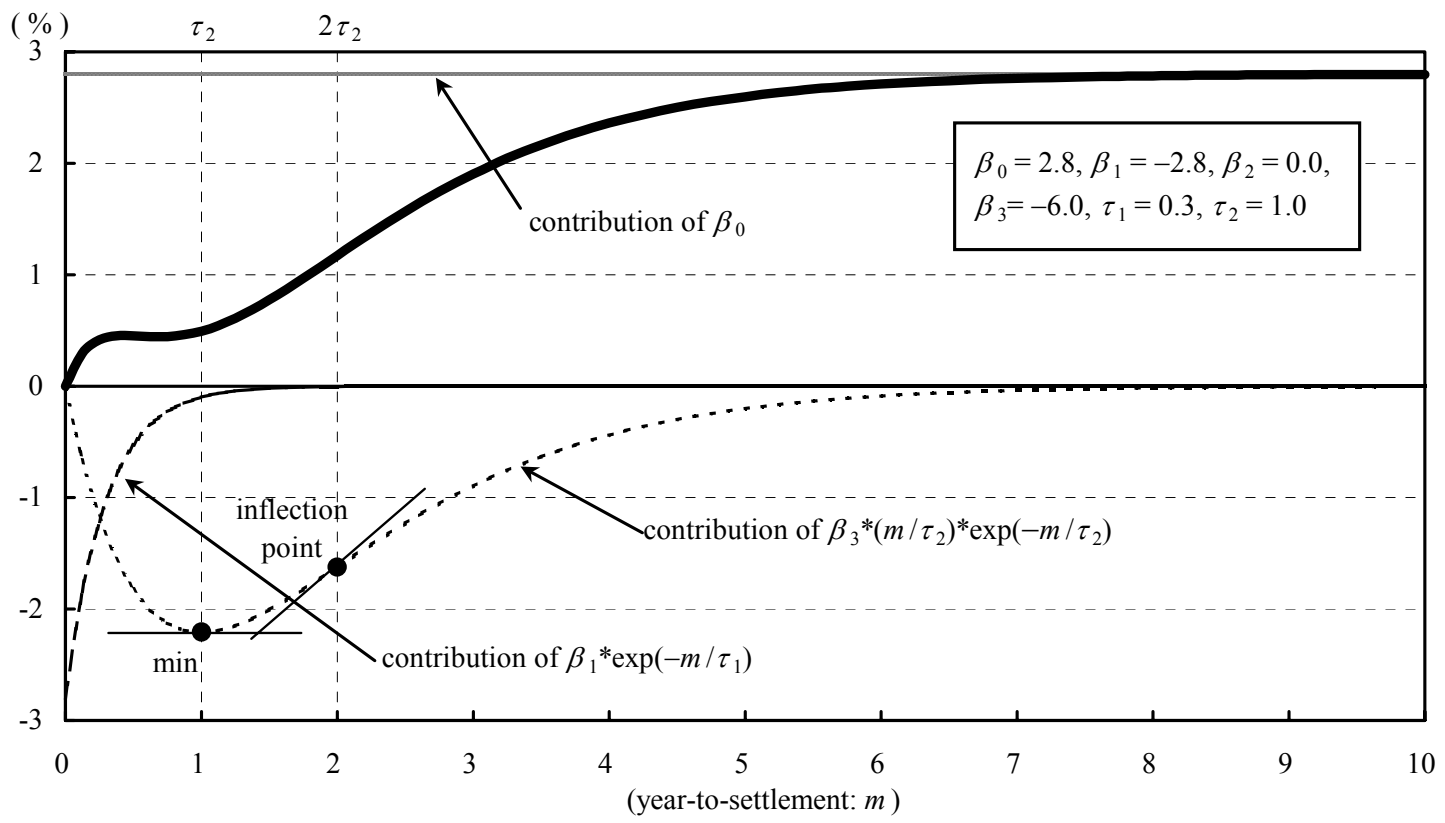

[B] A complex shape in the case of liquidity events

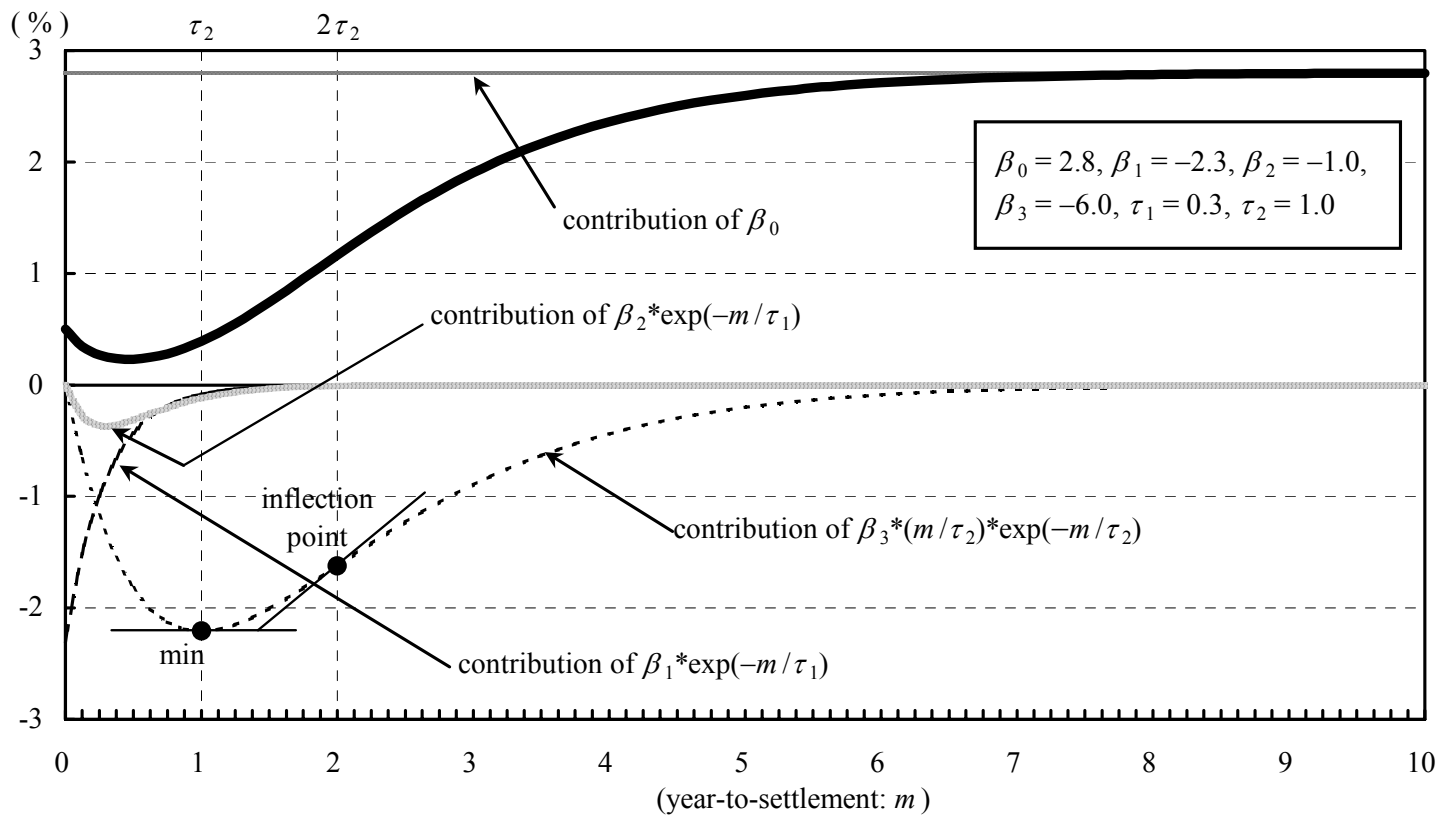

Notes: Forward rate and spot rate curves are computed by equations (1) and (3), respectively, using the following parameter values: $\beta_{0}=2.8, \beta_{1}=-2.8, \beta_{2}=0.0, \beta_{3}=-6.0, \tau_{1}=0.3, \tau_{2}=1.0$ for the upper panel; and $\beta_{0}=2.8, \beta_{1}=-2.3, \beta_{2}=-1.0, \beta_{3}=-6.0, \tau_{1}=0.3, \tau_{2}=1.0$ for the lower panel. 


\section{CESifo Working Paper Series}

(for full list see www.cesifo.de)

1070 Jay Pil Choi, Patent Pools and Cross-Licensing in the Shadow of Patent Litigation, November 2003

1071 Martin Peitz and Patrick Waelbroeck, Piracy of Digital Products: A Critical Review of the Economics Literature, November 2003

1072 George Economides, Jim Malley, Apostolis Philippopoulos, and Ulrich Woitek, Electoral Uncertainty, Fiscal Policies \& Growth: Theory and Evidence from Germany, the UK and the US, November 2003

1073 Robert S. Chirinko and Julie Ann Elston, Finance, Control, and Profitability: The Influence of German Banks, November 2003

1074 Wolfgang Eggert and Martin Kolmar, The Taxation of Financial Capital under Asymmetric Information and the Tax-Competition Paradox, November 2003

1075 Amihai Glazer, Vesa Kanniainen, and Panu Poutvaara, Income Taxes, Property Values, and Migration, November 2003

1076 Jonas Agell, Why are Small Firms Different? Managers’ Views, November 2003

1077 Rafael Lalive, Social Interactions in Unemployment, November 2003

1078 Jean Pisani-Ferry, The Surprising French Employment Performance: What Lessons?, November 2003

1079 Josef Falkinger, Attention, Economies, November 2003

1080 Andreas Haufler and Michael Pflüger, Market Structure and the Taxation of International Trade, November 2003

1081 Jonas Agell and Helge Bennmarker, Endogenous Wage Rigidity, November 2003

1082 Fwu-Ranq Chang, On the Elasticities of Harvesting Rules, November 2003

1083 Lars P. Feld and Gebhard Kirchgässner, The Role of Direct Democracy in the European Union, November 2003

1084 Helge Berger, Jakob de Haan and Robert Inklaar, Restructuring the ECB, November 2003

1085 Lorenzo Forni and Raffaela Giordano, Employment in the Public Sector, November 2003 
1086 Ann-Sofie Kolm and Birthe Larsen, Wages, Unemployment, and the Underground Economy, November 2003

1087 Lars P. Feld, Gebhard Kirchgässner, and Christoph A. Schaltegger, Decentralized Taxation and the Size of Government: Evidence from Swiss State and Local Governments, November 2003

1088 Arno Riedl and Frans van Winden, Input Versus Output Taxation in an Experimental International Economy, November 2003

1089 Nikolas Müller-Plantenberg, Japan’s Imbalance of Payments, November 2003

1090 Jan K. Brueckner, Transport Subsidies, System Choice, and Urban Sprawl, November 2003

1091 Herwig Immervoll and Cathal O'Donoghue, Employment Transitions in 13 European Countries. Levels, Distributions and Determining Factors of Net Replacement Rates, November 2003

1092 Nabil I. Al-Najjar, Luca Anderlini \& Leonardo Felli, Undescribable Events, November 2003

1093 Jakob de Haan, Helge Berger and David-Jan Jansen, The End of the Stability and Growth Pact?, December 2003

1094 Christian Keuschnigg and Soren Bo Nielsen, Taxes and Venture Capital Support, December 2003

1095 Josse Delfgaauw and Robert Dur, From Public Monopsony to Competitive Market. More Efficiency but Higher Prices, December 2003

1096 Clemens Fuest and Thomas Hemmelgarn, Corporate Tax Policy, Foreign Firm Ownership and Thin Capitalization, December 2003

1097 Laszlo Goerke, Tax Progressivity and Tax Evasion, December 2003

1098 Luis H. B. Braido, Insurance and Incentives in Sharecropping, December 2003

1099 Josse Delfgaauw and Robert Dur, Signaling and Screening of Workers' Motivation, December 2003

1100 Ilko Naaborg, Bert Scholtens, Jakob de Haan, Hanneke Bol and Ralph de Haas, How Important are Foreign Banks in the Financial Development of European Transition Countries?, December 2003

1101 Lawrence M. Kahn, Sports League Expansion and Economic Efficiency: Monopoly Can Enhance Consumer Welfare, December 2003

1102 Laszlo Goerke and Wolfgang Eggert, Fiscal Policy, Economic Integration and Unemployment, December 2003 
1103 Nzinga Broussard, Ralph Chami and Gregory D. Hess, (Why) Do Self-Employed Parents Have More Children?, December 2003

1104 Christian Schultz, Information, Polarization and Delegation in Democracy, December 2003

1105 Daniel Haile, Abdolkarim Sadrieh and Harrie A. A. Verbon, Self-Serving Dictators and Economic Growth, December 2003

1106 Panu Poutvaara and Tuomas Takalo, Candidate Quality, December 2003

1107 Peter Friedrich, Joanna Gwiazda and Chang Woon Nam, Development of Local Public Finance in Europe, December 2003

1108 Silke Uebelmesser, Harmonisation of Old-Age Security Within the European Union, December 2003

1109 Stephen Nickell, Employment and Taxes, December 2003

1110 Stephan Sauer and Jan-Egbert Sturm, Using Taylor Rules to Understand ECB Monetary Policy, December 2003

1111 Sascha O. Becker and Mathias Hoffmann, Intra-and International Risk-Sharing in the Short Run and the Long Run, December 2003

1112 George W. Evans and Seppo Honkapohja, The E-Correspondence Principle, January 2004

1113 Volker Nitsch, Have a Break, Have a ... National Currency: When Do Monetary Unions Fall Apart?, January 2004

1114 Panu Poutvaara, Educating Europe, January 2004

1115 Torsten Persson, Gerard Roland, and Guido Tabellini, How Do Electoral Rules Shape Party Structures, Government Coalitions, and Economic Policies? January 2004

1116 Florian Baumann, Volker Meier, and Martin Werding, Transferable Ageing Provisions in Individual Health Insurance Contracts, January 2004

1117 Gianmarco I.P. Ottaviano and Giovanni Peri, The Economic Value of Cultural Diversity: Evidence from US Cities, January 2004

1118 Thorvaldur Gylfason, Monetary and Fiscal Management, Finance, and Growth, January 2004

1119 Hans Degryse and Steven Ongena, The Impact of Competition on Bank Orientation and Specialization, January 2004

1120 Piotr Wdowinski, Determinants of Country Beta Risk in Poland, January 2004 
1121 Margarita Katsimi and Thomas Moutos, Inequality and Redistribution via the Public Provision of Private Goods, January 2004

1122 Martin Peitz and Patrick Waelbroeck, The Effect of Internet Piracy on CD Sales: CrossSection Evidence, January 2004

1123 Ansgar Belke and Friedrich Schneider, Privatization in Austria: Some Theoretical Reasons and First Results About the Privatization Proceeds, January 2004

1124 Chang Woon Nam and Doina Maria Radulescu, Does Debt Maturity Matter for Investment Decisions?, February 2004

1125 Tomer Blumkin and Efraim Sadka, Minimum Wage with Optimal Income Taxation, February 2004

1126 David Parker, The UK's Privatisation Experiment: The Passage of Time Permits a Sober Assessment, February 2004

1127 Henrik Christoffersen and Martin Paldam, Privatization in Denmark, 1980-2002, February 2004

1128 Gregory S. Amacher, Erkki Koskela and Markku Ollikainen, Deforestation, Production Intensity and Land Use under Insecure Property Rights, February 2004

1129 Yin-Wong Cheung, Javier Gardeazabal, and Jesús Vázquez, Exchange Rate Dynamics: Where is the Saddle Path?, February 2004

1130 Alberto Alesina and Guido Tabellini, Bureaucrats or Politicians?, February 2004

1131 Gregory S. Amacher, Erkki Koskela, and Markku Ollikainen, Socially Optimal Royalty Design and Illegal Logging under Alternative Penalty Schemes, February 2004

1132 David M. Newbery, Privatising Network Industries, February 2004

1133 Charles Yuji Horioka, The Stagnation of Household Consumption in Japan, February 2004

1134 Eiji Fujii, Exchange Rate Pass-Through in the Deflationary Japan: How Effective is the Yen's Depreciation for Fighting Deflation?, February 2004

1135 Mark M. Spiegel and Nobuyoshi Yamori, Determinants of Voluntary Bank Disclosure: Evidence from Japanese Shinkin Banks, Febrary 2004

1136 Robert Dekle and Kenneth Kletzer, Deposit Insurance, Regulatory Forbearance and Economic Growth: Implications for the Japanese Banking Crisis, February 2004

1137 Takatoshi Ito and Kimie Harada, Bank Fragility in Japan, 1995-2003, February 2004

1138 Kunio Okina and Shigenori Shiratsuka, Policy Duration Effect under Zero Interest Rates: An Application of Wavelet Analysis, February 2004 